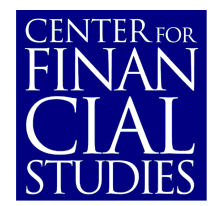

No. $2003 / 41$

\title{
Permanent and Transitory Policy Shocks in an Empirical Macro Model with Asymmetric Information
}

Sharon Kozicki and P.A. Tinsley

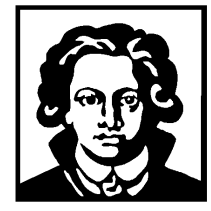

Center for Financial Studies 


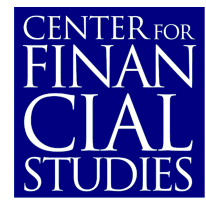

\section{Center for Financial Studies}

The Center for Financial Studies is a nonprofit research organization, supported by an association of more than 120 banks, insurance companies, industrial corporations and public institutions. Established in 1968 and closely affiliated with the University of Frankfurt, it provides a strong link between the financial community and academia.

The CFS Working Paper Series presents the result of scientific research on selected topics in the field of money, banking and finance. The authors were either participants in the Center's Research Fellow Program or members of one of the Center's Research Projects.

If you would like to know more about the Center for Financial Studies, please let us know of your interest.

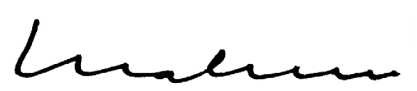

Prof. Dr. Jan Pieter Krahnen

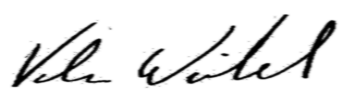

Prof. Volker Wieland, Ph.D.

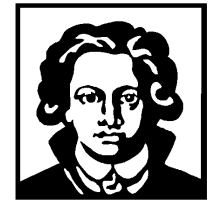




\title{
Permanent and Transitory Policy Shocks in an Empirical Macro Model with Asymmetric Information
}

\author{
Sharon Kozicki and P.A. Tinsley
}

This version: October 28, 2003

\begin{abstract}
:
Despite a large literature documenting that the efficacy of monetary policy depends on how inflation expectations are anchored, many monetary policy models assume: (1) the inflation target of monetary policy is constant; and, (2) the inflation target is known by all economic agents. This paper proposes an empirical specification with two policy shocks: permanent changes to the inflation target and transitory perturbations of the short-term real rate. The public sector cannot correctly distinguish between these two shocks and, under incomplete learning, private perceptions of the inflation target will not equal the true target. The paper shows how imperfect policy credibility can affect economic responses to structural shocks, including transition to a new inflation target - a question that cannot be addressed by many commonly used empirical and theoretical models. In contrast to models where all monetary policy actions are transient, the proposed specification implies that sizable movements in historical bond yields and inflation are attributable to perceptions of permanent shocks in target inflation.
\end{abstract}

JEL Classification: E43, E52, D82, D83

Keywords: transmission mechanism, learning, policy credibility, time-varying natural rate, shifting endpoint, inflation target, term structure of interest rates

An earlier version was presented at the 2003 conference on "Expectations, Learning, and Monetary Policy" sponsored by the Center for Financial Studies, the Deutsche Bundesbank, and the Journal of Economic Dynamics and Control in Eltville, Germany, the 1999 American Economic Association annual meetings, the 1999 Conference on Computing in Economics and Finance of the Society of Computational Economics, the Federal Reserve Board, and the Federal Reserve Bank of Kansas City. We received many constructive comments from Michael Binder, William Branch, Alex Cukierman, and Reinhard Tietz for which we are very grateful. Thanks also to Matthew Cardillo for excellent research assistance.

Authors' addresses are: Federal Reserve Bank of Kansas City, 925 Grand Boulevard, Kansas City, MO, 64198 USA, skozicki@frbkc.org; and Faculty of Economics and Politics, University of Cambridge, Cambridge CB3 9DD, UK, ptinsley@econ.cam.ac.uk.

The views expressed are those of the authors and do not necessarily represent those of the Federal Reserve Bank of Kansas City or the Federal Reserve Board. 


\section{Introduction}

Many models that are used to evaluate monetary policy assume, either explicitly or implicitly, that (1) the inflation target of monetary policy is constant over the period being analyzed; and, (2) the inflation target is known by all economic agents. Because the actual and perceived inflation targets are equal and fixed, long-horizon expectations are independent of short-run policy in such models. ${ }^{1}$ Consequently, all monetary policy actions are transient, and monetary policy appears to contribute only modestly to postwar fluctuations in bond rates and economic activity.

The assumption that the inflation target is fully credible is surprisingly prevalent in recent studies that examine historical policy or evaluate alternative policies. The literature that evaluates policy alternatives under a constant and credible inflation target is vast. Optimizing models used to evaluate alternative monetary policies, such as those reviewed in Taylor (1999), generally assume a constant inflation target is common knowledge. Likewise, standard atheoretical empirical analyses of policy effects implicitly assume a fixed policy target or stationary nominal anchor. As noted by Kozicki and Tinsley (2001a), VARs containing the levels of inflation and nominal interest rates imply constant and known natural rates for those variables.

The traditional assumption that policy objectives were known to the private sector was accompanied in early studies by an emphasis on the real effects of unanticipated changes in monetary policy, such as Lucas (1973) and Sargent and Wallace (1976). Because imperfectly observed policy is equivalent to unanticipated policy, several early studies noted that monetary policy could have larger real effects in learning or filtering transitions between persistent shifts in policy, such as Taylor (1980), Meyer and Webster (1982), and

\footnotetext{
${ }^{1}$ The conclusion that long-run expectations are independent of short-run policy presumes that the policy being followed is consistent with the goals of policy. For example, a Taylor-type (1993) interest rate rule with an explicit numerical inflation target that doesnt satisfy the Taylor principle would generally lead to explosive inflation and explosive private-sector inflation forecasts. Such a policy rule would be inconsistent with the inflation target.
} 
Cukierman and Meltzer (1986). In subsequent literature, the introduction of nominal frictions permitted real effects of expected monetary policy. By contrast with earlier emphasis on the strength of unanticipated policy under learning, more recent papers indicate that expected policy effects can be significantly attenuated if private agents are not instantly aware of shifts in policy targets, such as the lengthy learning lags estimated in Kozicki and Tinsley (2001a, 2001b).

Accounting for imperfect policy credibility and learning is particularly important in the context of the nonstationary behavior of postwar U.S. inflation. Regime-switching models fit to U.S. inflation include, Brunner (1991), Evans and Wachtel (1993), Evans and Lewis (1995), and Garcia and Perron (1996). Levin and Piger (2003) present evidence for a one-time break in the mean inflation rates of twelve industrial countries, including the U.S., over a 1984-2002 sample. Relaxing the assumption of a fixed number of regimes and using samples from the 1960s through the 1990s, Kozicki and Tinsley (2001a, 2001b, and 2002) provide empirical evidence on nonstationary movements in the mean of inflation and suggest these reflect shifts in private agent perceptions of the policy target for inflation.

Of course, evidence of mean shifts in the inflation process may be consistent with an unknown, but fixed, inflation target and time-varying perceptions. For example, Orphanides and Williams (2003) illustrate that the perceived inflation target estimated by learning agents may increase in response to unfavorable inflation shocks, even if the true target is invariant. The divergence of perceived and actual inflation targets is larger for policies that place more emphasis on real output stability, providing one interpretation of high and rising levels of inflation in the 1970s. An alternative historical interpretation includes the prospect that the effective inflation target drifted higher in the 1970s, in part due to partial accommodation of sizeable supply shocks, followed in the 1980s by rapid reductions in the true policy target but much slower declines in the perceived inflation target. While the latter view is more consistent with econometric specifications used in this paper, both 
interpretations share the common assumptions of asymmetric policy information and of significant deviations of private sector long-run inflation forecasts from the true inflation target.

Because shifts in the perceived inflation target do not always appear to coincide with possible shifts in the inflation target of the monetary authority, asymmetric information on the part of private sector agents and the monetary authority seems more plausible than the standard assumption of full information. In this paper, such deviations of the perceived target from the true target provide evidence of imperfect policy credibility, where credible policy is defined as the equivalence of the natural rate of private sector inflation forecasts with the inflation target of the monetary authority.

Recent macro models with shifting policy regimes include the atheoretic empirical model of Cogley and Sargent (2003), the calibrated dynamic stochastic general equilibrium models of Erceg and Levin (2003) and Andolfatto and Gomme (2003), and Bayesian estimates of the DSGE models in Schorfheide (2003). Similar to learning specifications in the last two citations, private agent learning in the current paper is based on agent responses to the prediction error of the short-term interest rate controlled by monetary policy.

This paper reexamines evidence on the monetary transmission mechanism using a small empirical model of the U.S. economy. The model specification admits imperfect policy credibility by relaxing the standard assumptions of full information and a constant inflation target. Monetary policy is summarized by a policy rule with the federal funds rate smoothly adjusted in response to cyclical movements in economic activity, deviations of inflation from the inflation target, inflation target shifts, and transitory policy shocks. Unlike typical empirical models with a single policy shock, the model in this paper includes two types of policy shocks: permanent shifts to the inflation target and transitory perturbations of the federal funds rate. Because agents do not observe the true target, they cannot distinguish permanent and transitory policy shocks in the short run. 
In the model, the inflation goal of policy is assumed only to be known by the monetary authority, although the observable policy instrument provides noisy information about the target. Private sector agents must form perceptions of the inflation goal of policy and these perceptions influence nominal price setting. The model specification admits a possibly shifting inflation target of monetary policy as well as a perceived inflation target that also may vary over time. This framework can apply to countries with announced inflation targets as well as to those without, since announced targets may not be fully credible.

Simulations of the model illustrate how imperfect policy credibility can affect transition to a new inflation target, a question that cannot be addressed by many commonly used empirical and theoretical models. In contrast to models where all monetary policy actions are transient, the model generates sizable monetary policy contributions to historical fluctuations in inflation and bond yields attributable to permanent target shocks. A consequence of the estimated learning structure is that the perceived inflation target remains elevated well into the 1980s, holding up bond rates long after the inflation target and inflation have retreated.

Taylor (1980) and Meyer and Webster (1982) examine the implications of a permanent policy shock in models with a money growth rule and learning behavior on the part of the private sector. These papers examined the behavior of inflation without references to actual or perceived inflation targets or long-term interest rates. Effects of changes in perceived inflation targets on long-term bond rates are analyzed in Fuhrer (1996), Huh and Lansing (1998), and Kozicki and Tinsley (2001a, 2001b). Whereas Fuhrer's analysis assumes shifts in policy regimes are instantly known to private agents, the remaining studies incorporate asymmetric information assumptions. The current paper provides explicit contrasts between empirical estimates of the time-varying inflation target and private sector perceptions of the inflation target.

Following the seminal work of Sargent (1993) and Evans and Honkapohja (2001), models 
of learning by agents often specify that agent expectations are generated by recursive least squares (RLS) estimates of linear forecast functions (perceived laws of motion). RLS learning is a natural assumption for models that are known to have fixed coefficients. However, RLS learning is likely to be less relevant for economies with time-varying structures (including the case of shifting inflation targets).

Alternative learning methods for time-varying shifts include change point models, explored by Kozicki and Tinsley (2001a), and variants of bounded memory learning, such as rolling sample estimation or constant gain estimation, illustrated in the simulations of Orphanides and Williams (2003). Other examples of constant gain learning in the context of rare permanent real shocks are Bullard and Duffy (2003) and Bullard and Eusepi (2003). As noted in these studies, benefits of constant gain learning include both recursive tractability and sensitivity to recent observations that incorporate the current shifts of the underlying economic structure. Although bounded memory learning can converge to a rational expectations equilibrium in a deterministic model, convergence will not occur in models with stochastic shocks, Evans and Honkapohja (2003). Consequently, an offsetting cost of constant gain learning, even if shifts are infrequent, is that the economy will not converge to the new rational expectations equilibrium path but to an ergodic distribution about the REE. Intuitively, smaller rolling sample spans or larger constant gains provide a tradeoff between faster recognition of new shifts and higher "excess" volatility in steady states.

In this paper, implications for the transmission mechanism of possibly shifting policy goals, imperfect policy credibility (or asymmetric information), and private sector learning are examined by comparing the properties of two empirical models of the U.S. economy: a model with time-varying policy goals and learning; and, a model with similar dynamic structure but with a constant and credible inflation target. Many of the studies cited earlier address asymmetric information and learning issues using analytical or calibrated models. 
By contrast, the analysis of this paper is based on an estimated empirical model with a shifting inflation target. Time variation of the inflation target incorporates exogenous and endogenous sources, and is not limited to a small number of policy regimes. Additional contributions of the paper include a model specification with both permanent and transitory policy shocks, explicit estimation of the implicit actual and perceived inflation target series, and dynamic analysis linking private sector perceptions of target shocks to the behavior of long-term interest rates.

The next section introduces the empirical model with a time-varying inflation target, asymmetric information, and learning. Section 3 discusses estimation procedures. Estimation results are presented for both the time-varying target model and a model that assumes the inflation target is constant and credible. Kalman filter estimates of the perceived inflation target and the inflation target obtained from the time-varying model are presented. Section 4 compares the dynamic responses of the two systems to transitory structural shocks and explores responses to target and expectations shocks in the time-varying target model. Three important results are obtained. First, in general, responses in the time-varying target model tend to be smaller and less persistent than those in the constant target model. Second, in contrast to the transitory effects obtained with the constant-target model, aggregate supply shocks have permanent effects on inflation and nominal interest rates in the time-varying-target model as a consequence of partial policy accommodation of supply shocks. Third, the "price puzzle" in the response of inflation to a transitory policy shock disappears in the model with a time-varying target and learning. Section 5 explores the role of the speed of learning in the time-varying target model. The speed of learning is shown to influence the volatility and persistence of responses to policy shocks. As the speed of learning increases, i.e., with an improvement in credibility, real costs associated with the transition to a new inflation regime are smaller. However, faster learning also implies greater volatility in inflation target perceptions in response to transitory policy 
shocks.

\section{The model}

As demonstrated in Kozicki and Tinsley (2002), shifts in the perceived inflation target, imperfect policy credibility, and time-variation in the persistence of inflation appear to be important empirical properties of U.S. inflation. The motivation of the current paper is to specify a simple dynamic macro model that can generate these key empirical features.

Two issues influenced the selection of a model with essentially a VAR-like structure. First, good empirical fit was seen as essential to providing a realistic assessment of the economic significance of shifting inflation targets and asymmetric information. Second, replication of observed dynamic interactions is important for examining policy transmission and long-run forecasts.

The selected specification is a bit more general than a standard VAR. As with traditional models, dynamic interactions among deviations of variables from their natural rates are captured in a linear time-series structure. However, whereas standard models implicitly assume that the natural rates of variables are constant and known, the current model is augmented to allow for shifts of the inflation target and asymmetric policy information. ${ }^{2}$ Kozicki and Tinsley (2002) estimated a perceived inflation target series from a similar VAR-like model with shifting endpoints, but did not distinguish between target shifts and perceived target shifts.

The asymmetric information assumption implies that the inflation target is not known by the private sector. ${ }^{3}$ Even if the target were to be announced, the model assumes that

\footnotetext{
${ }^{2}$ The term "natural rate" is used to refer to the long-run equilibrium or attractor of a variable. The term "anchor" appears to be traditionally used in literature to denote a nominal natural rate, and the terms "steady-state" and "mean" often imply constants.

${ }^{3}$ The source of asymmetric information in this study is lack of knowledge on the part of the private sector about the level and evolution of the inflation target, and about transitory and permanent policy shocks. Other formulations of asymmetric information include private sector uncertainty about policymaker preferences over real activity versus inflation as in Cukierman and Meltzer (1986) and Tetlow and von zur Muehlen (2001), and different models of the transmission mechanism or other aspects of model specification
} 
such announcements need not be credible. Consequently, the private sector must form beliefs about the inflation target. The model is augmented to capture learning behavior on the part of the private sector and includes a time-varying perceived inflation target that will tend to differ from the possibly time-varying inflation target.

The model includes expressions for the dynamics of four variables, the output gap $\left(y_{t}\right)$, inflation $\left(\pi_{t}\right)$, the federal funds rate $\left(r_{t}\right)$, and a long-term interest rate $\left(R_{t}\right)$, and expressions that describe the evolution of time-variation, if any, in natural rates. A long-term interest rate has been included so that policy transmission issues associated with long-horizon expectations can be better addressed. In particular, long-term interest rates depend on private sector long-horizon forecasts of inflation, and those forecasts will be influenced in the short-run by shifts in the perceived inflation target.

In model expressions, variables are expressed as deviations from natural rates. The natural rate of the output gap is assumed to be constant $(\bar{y})$ and equal to zero, although empirical estimates may differ from zero over finite samples. The natural rate of inflation equals the perceived inflation target $\left(\pi^{P}(t)\right)$, which may be time varying. The natural real rate is assumed to be constant $(\bar{r})$. The perceived inflation target, $\pi^{P}(t)$, appears in the natural rates of both short-term and long-term nominal interest rates as it anchors the expected inflation component of nominal interest rates. Thus, the natural rate of the long-term nominal interest rate is equal to the sum of the natural real rate, the term premium natural rate $(\bar{\theta})$ which is assumed to be constant, and the perceived inflation target: $\bar{r}+\bar{\theta}+\pi^{P}(t)$. The natural rate of the federal funds rate is the sum of the natural real rate and the perceived inflation target $\left(\bar{r}+\pi^{P}(t)\right)$. The policy equation also captures the federal funds rate response to the deviation of recent inflation from the policy target for inflation.

Expressions for the output gap, inflation, and the long-term interest rate are similar employed by the private sector and policymakers. 
to VAR equations with lags of the output gap, inflation, the federal funds rate, and the long-term interest rate included in each. Monetary policy is modeled using an estimated Taylor (1993) rule with smoothing. Smoothing refers to the appearance of the lagged funds rate in the policy rule. The lagged funds rate is often interpreted as capturing smoothing behavior on the part of policymakers who may prefer to act gradually in the presence of uncertainties about the structure of the economy. Gradualism may also reduce financial market activity and increase economic responses to policy actions by magnifying the response of other market interest rates to policy actions. See, for example, the discussion in Amato and Laubach (1999) and English, Nelson, and Sack (2003). Empirical estimates of Taylor rules with smoothing are provided in Kozicki (1999) and Sack and Wieland (2000). The policy rule specifies that the deviation of the federal funds rate from its natural rate is determined by policy responses to the output gap, the deviation of inflation over the previous four quarters $\left(\bar{\pi}_{t, 4}\right)$ from the inflation target, a lagged funds rate deviation to capture policy smoothing, and a transitory policy shock $\left(u_{r, t}\right)$ :

$$
r_{t}=\bar{r}+\pi^{P}(t)+\gamma_{y}\left(y_{t}-\bar{y}\right)+\gamma_{\pi}\left(\bar{\pi}_{t, 4}-\pi^{T}(t)\right)+\rho\left(r_{t-1}-\bar{r}-\pi^{P}(t)\right)+u_{r, t}
$$

where $\bar{\pi}_{t, 4} \equiv \sum_{i=0}^{3} \pi_{t-i}$.

Structural shocks to aggregate demand, aggregate supply, the funds rate (a transient policy shock), and the term premium are identified by assuming a recursive causal ordering with the output gap ordered first, followed by inflation, the federal funds rate, and the long-term interest rate. Thus, the assumed causal ordering implies that long-term interest rates respond contemporaneously to the aggregate demand, aggregate supply, transitory policy, and term premium shocks. The residual in the output gap equation is identified as an aggregate demand shock.

The inflation equation is a reduced-form Phillips curve. Inflation may respond contemporaneously to the aggregate demand shock, explaining a possible correlation 
between the output gap equation residual and the inflation equation residual. Inflation also responds to an aggregate supply (cost push) shock. A notable feature of the reduced form Phillips curve specification is that the sum of coefficients on lags of inflation deviations are not constrained to unity. However, because inflation only appears in the Phillips curve as the deviation from the perceived target, the expression does not exhibit a long-run tradeoff between inflation and the output gap.

A long-run tradeoff is absent because the policy rule in the model is such that positive excess demand can persist only if the inflation target is allowed to increase. The learning structure in the model is such that an increase in the target is eventually incorporated into an increase in the perceived target, and consequently to inflation. ${ }^{4}$ The policy rule structure assumes that monetary policy responds contemporaneously to the output gap and inflation, and thus to the aggregate demand and aggregate supply shocks. The funds rate also responds to the transitory policy shock (a liquidity supply shock).

The remaining equations of the model describe the evolution of the inflation target series and the perceived target series. The inflation target follows a martingale process so that changes in the inflation target series are not forecastable. The inflation target shifts with policy accommodation (if any) of aggregate supply shocks $\left(u_{S, t}\right)$, with deterministic regime change (in the early years of Volker's chairmanship of the Federal Reserve), or with exogenous permanent policy shocks $\left(u_{T, t}\right)$ :

$$
\pi^{T}(t+1)=\pi^{T}(t)+\eta d_{79-82}+c_{S T} u_{S, t}+u_{T, t}
$$

Regime change to bring inflation down following the appointment of Volker as chairman of the Federal Reserve is captured deterministically through the dummy variable $d_{79-82}$, set to one for the period 1979Q4 through 1982Q4 and zero at other times. As captured by

\footnotetext{
${ }^{4}$ Given the structure of the model, the monetary authority would be able to maintain permanent excess demand (i.e., output above potential) by allowing the inflation target and inflation to continue to increase without bound.
} 
the binary dummy, the inflation target was gradually changed by $\eta$ in each quarter of the 1979Q4 through 1982Q4 interval. A competing description is that the target was completely adjusted in one quarter, 1979Q4, but this provides a poor estimate of $\eta$. Increasing the period over which the target change occurred reduces the standard error of the estimate of $\eta$. The 1979Q4 to 1982Q4 interval is also a period when U.S. monetary policy targeted measures of the money supply and nonborrowed reserves, and there were several adjustments of targets and operating procedures.

Exogenous policy shocks may proxy for changes in the degree of conservatism of the Federal Open Market Committee (FOMC), at least to the extent that this accompanies a change in the composition of the FOMC, and importantly, the Chairman. Other possible explanations for target changes include partial accommodation of changing expectations of the private sector, as in Bullard and Cho (2002), or partial accommodation of movements in inflation, as in Gürkaynak, Sack, and Swanson (2003). The former is inconsistent with the target leading the perceived target, as was likely the case in the Volker disinflation. The latter might be seen as a reduced-form variant of partial accommodation of aggregate supply shocks as specified in this paper.

The evolution of the perceived inflation target incorporates learning behavior about the target on the part of the private sector. Several approaches to modeling learning behavior that could be used to close the model include recursive least squares learning, Markov switching, changepoint learning, and constant gain learning. In models with a fixed structure, recursive least squares estimates of parameters can converge to the true parameter values. However, recursive least squares loses its appeal in models with structural change as distant past observations are weighted equally to recent observations. Markov switching models are effective in specifications where there is advance knowledge of the number of regimes. However, empirical implementations do not accommodate regimes that have not yet occurred (with no data points in a regime, it is impossible to estimate the parameters 
that characterize the regime).

Kozicki and Tinsley (2001a and 2001b) use changepoint learning in a model with possibly multiple regimes when the number of regimes is not predetermined. Learning about target shifts is modeled by assuming agents use Andrews (1993) breakpoint tests to detect mean shifts in inflation. Learning lags are captured by dating expectations shifts according to the time at which agents could statistically detect mean shifts, which necessarily lags the actual occurrence of mean shifts. Heterogeneity of agents is captured using alternative implementations of the test based on the number of new observations collected prior to retesting. Kozicki and Tinsley (2001a) use multinominal logit aggregation of heterogeneous learning that allows weights on different breakpoint-test implementations to depend on recent performance. An advantage of changepoint learning is that it will converge in the absence of structural shifts. A disadvantage is that testing for change points is not amenable to recursive formulations.

Constant gain learning is similar to recursive least squares but gives more weight to more recent observations to capture effects of structural shifts. However, in the absence of shifts, constant gain learning will generate noisy estimates of parameters (natural rates) as disturbances to observable data series will be mapped into perceptions. Although changepoint learning and constant gain learning have very different properties, Kozicki and Tinsley (2001b) found that inflation-based constant gain learning in which the perceived target is updated in the direction of recent inflation $\left(\pi^{P}(t+1)=\pi^{P}(t)+\right.$ $\left.\kappa\left(\pi_{t}-\pi^{P}(t)\right)\right)$ approximated the estimated perceived inflation target constructed using changepoint-learning with heterogeneous agents.

This paper uses constant gain updating rules to model learning about structural shifts in the inflation target. The benefits of this approach include the potential for capturing permanent structural shifts, the adaptability to recursive formulations, and the absence of sharp prior requirements, such as advance knowledge of the number of policy regimes. The 
principal cost is the excess noise in estimated perceptions that occurs in the absence of structural shifts.

The constant-gain learning algorithm that was chosen differs from the inflation-based algorithm examined in Kozicki and Tinsley (2001b). Implicitly, inflation-based constant gain learning assumes considerable ignorance on the part of the private sector about the economic structure and requires policy actions to first influence aggregate demand, which in turn affects inflation, before the perceived target adjusts. However, additional lags in the learning process are by assumption. Given the structure of the model in the current paper, learning is based on unexpected movements in the funds rate as these are direct, but noisy, measurements of shifts in the inflation target. A funds rate that is higher than expected may reflect a permanent reduction in the inflation target or a transient positive policy shock to the funds rate, and vice versa. With policy response-based learning, movements in the perceived target may (but need not) lead inflation. By contrast, with inflation-based constant gain learning, inflation necessarily leads the perceived target. Effects of shocks will dissipate more slowly because inflation affects the perceived target and shifts in the perceived target feed back into inflation.

To isolate the effects of imperfect policy credibility, private sector agents are assumed to know the structure and parameters of the economy with the exception of the level and evolution of the inflation target and the transitory policy shock, $u_{r, t}$. Since they know the general form of the policy rule-including policy response coefficients to the output gap, $\gamma_{y}$, to inflation deviations, $\gamma_{\pi}$, and to the policy smoothing parameter, $\rho$-the deviation of the federal funds rate, $r_{t}$, from private sector expectations of the federal funds rate, $r_{t}^{e}$, provides noisy information on the deviation of the perceived target, $\pi^{P}(t)$, from the true target, $\pi^{T}(t)$,

$$
r_{t}-r_{t}^{e}=\gamma_{\pi}\left(\pi^{P}(t)-\pi^{T}(t)\right)+u_{r, t}
$$

Private sector learning about the target is modeled by assuming agents use a perpetual 
learning algorithm that places greater weight on more recent observations of the funds rate expectations error:

$$
\pi^{P}(t+1)=\pi^{P}(t)-\delta\left(r_{t}-r_{t}^{e}\right)+u_{P, t}
$$

where $u_{P, t}$ is an expectations shock. After substituting for the funds rate expectations error from (3), perceived target learning satisfies:

$$
\pi^{P}(t+1)=\left(1-\delta \gamma_{\pi}\right) \pi^{P}(t)+\delta \gamma_{\pi} \pi^{T}(t)-\delta u_{r, t}+u_{P, t}
$$

For non-zero $\delta$, the target and perceived target are cointegrated, so that for $0<\delta \gamma_{\pi}<1$ and in the absence of future shocks, the perceived target will gradually adjust towards the target. ${ }^{5}$ This adjustment comes, not from direct knowledge of the target, but from information about the gap between the target and perceived target that is contained in the market prediction error for the funds rate.

\section{Estimation Results}

Quarterly data from 1960 through 2001 was used for the empirical analysis. Inflation is measured as the quarterly percent change in the chain-price index for core personal consumption expenditures. The output gap is measured as the percent deviation between quarterly real GDP and Congressional Budget Office estimates of quarterly potential real GDP. The vintage of these data is the first quarter of 2003. The quarterly averages of the federal funds rate and of the constant maturity 10-year yield on U.S. Treasury bonds are used as the short-term policy rate and the long-term interest rate, respectively. All series are expressed at annual rates. The output and inflation series are seasonally adjusted.

The model to be estimated includes:

\footnotetext{
${ }^{5}$ However, as long as monetary policy is subject to transitory shocks, the perceived target will continue to fluctuate about the true target.
} 
- Measurement equations

$$
\begin{aligned}
{\left[\begin{array}{c}
y_{t} \\
\pi_{t} \\
R_{t}
\end{array}\right] } & =\left[\begin{array}{c}
\bar{y} \\
\pi^{P}(t) \\
\bar{r}+\pi^{P}(t)+\bar{\theta}
\end{array}\right]+\beta(L)\left[\begin{array}{c}
y_{t-1}-\bar{y} \\
\pi_{t-1}-\pi^{P}(t) \\
R_{t-1}-\bar{r}-\pi^{P}(t)-\bar{\theta} \\
r_{t-1}-\bar{r}-\pi^{P}(t)
\end{array}\right]+\left[\begin{array}{c}
\epsilon_{y, t} \\
\epsilon_{\pi, t} \\
\epsilon_{R, t}
\end{array}\right] \\
r_{t} & =\bar{r}+\pi^{P}(t)+\gamma_{y}\left(E_{t-1} y_{t}-\bar{y}\right)+\gamma_{\pi}\left(E_{t-1} \bar{\pi}_{t, 4}-\pi^{T}(t)\right)+\rho\left(r_{t-1}-\bar{r}-\pi^{P}(t)\right)+\epsilon_{r, t},
\end{aligned}
$$

- Transition equations

$$
\left[\begin{array}{l}
\pi^{T}(t+1) \\
\pi^{P}(t+1)
\end{array}\right]=\left[\begin{array}{cc}
1 & 0 \\
\delta \gamma_{\pi} & 1-\delta \gamma_{\pi}
\end{array}\right]\left[\begin{array}{c}
\pi^{T}(t) \\
\pi^{P}(t)
\end{array}\right]+\left[\begin{array}{l}
\eta \\
0
\end{array}\right] d_{79-82}+\left[\begin{array}{c}
\epsilon_{T, t} \\
\epsilon_{P, t}
\end{array}\right]
$$

- Structural shock identification

$$
\left[\begin{array}{c}
\epsilon_{y, t} \\
\epsilon_{\pi, t} \\
\epsilon_{R, t} \\
\epsilon_{r, t} \\
\epsilon_{T, t} \\
\epsilon_{P, t}
\end{array}\right]=\left[\begin{array}{cccccc}
1 & 0 & 0 & 0 & 0 & 0 \\
c_{D S} & 1 & 0 & 0 & 0 & 0 \\
c_{D \tau} & c_{S \tau} & 1 & c_{r \tau} & 0 & 0 \\
\gamma_{y} & \gamma_{\pi} / 4 & 0 & 1 & 0 & 0 \\
0 & c_{S T} & 0 & 0 & 1 & 0 \\
0 & 0 & 0 & -\delta & 0 & 1
\end{array}\right]\left[\begin{array}{c}
u_{D, t} \\
u_{S, t} \\
u_{\tau, t} \\
u_{r, t} \\
u_{T, t} \\
u_{P, t}
\end{array}\right]
$$

where $E_{t-1} y_{t}$ and $E_{t-1} \pi_{t}$ (the latter enters through $\left.E_{t-1} \bar{\pi}_{t, 4}\right)$ are conditional expectations formed from the output gap and inflation equations, and $u_{D}, u_{S}, u_{\tau}, u_{r}, u_{T}$, and $u_{P}$ are serially uncorrelated and mutually uncorrelated structural shocks to aggregate demand, aggregate supply, the term premium, monetary policy (transitory), monetary policy (permanent), and expectations. These structural shocks are assumed to be Normally distributed with mean zero and variance $\sigma_{i}^{2}$ for $i=D, S, \tau, r, T, P$. The lag polynomial $\beta(L)$ allows for four lags. The inflation target of policy and the perceived target are unobserved variables to be jointly estimated with the rest of the model. The model is estimated using maximum likelihood with Kalman filters used to extract the time-varying paths of the inflation target and the perceived inflation target. The target and perceived target are initialized using a diffuse prior.

Coefficients of the matrix lag polynomial are assumed to be constant over the entire sample. A consequence of this assumption is that any structural breaks will be mapped 
into either shifts in the inflation target or shifts in the perceived target. This approach contrasts with that in Clarida, Gali, and Gertler (1998), where it is assumed the inflation target is fixed over a post-1979 sample. They captured structural breaks in the policy function by estimating two policy functions: one for the period ending in 1979 and one for the period since 1979. While policy function parameters differed across subsamples, they were assumed to be constant within each subsample. Clarida, Gali, and Gertler concluded that the inflation target has been constant, and roughly equal to 4 percent, since 1979 .

To assess the implications of possibly shifting targets and imperfect policy credibility on model dynamics, a comparison model with a constant known target was estimated. This "constant" model is closer in structure to a typical VAR and includes the four observable model variables: the output gap, inflation, the federal funds rate, and a long-term interest rate. However, as in the time-varying target model, the funds rate equation has been replaced by a Taylor rule with smoothing. Structural shocks to aggregate demand, aggregate supply, monetary policy, and the term premium are identified using the same causal ordering as in the model that allowed time variation in the target and perceived target. The "constant" model was estimated using a generalized version of the seemingly unrelated regressors methodology to account for cross-equation restrictions and correlations between equation residuals. Estimates of the coefficients that summarize the structural relationships between the residuals and estimates of the standard errors of the structural shocks are obtained using a Cholesky decomposition of the estimated residual covariance matrix.

Estimation results for both the time-varying target model and the constant target model are provided in Tables 1-3. The model specifications are similar in many ways. In both models the natural rate of the output gap is insignificantly different from zero, the equilibrium real rate is close to 3 percent and the term premium natural rate is close to 0.7 percent (Table 1). In addition, estimates of parameters that identify structural shocks $(c .$. that are common to the two models, and estimates of standard errors of aggregate demand 
shocks, aggregate supply shocks and term premium shocks are similar.

The main difference between the policy rules in the two models is the estimated degree of policy smoothing. In both models, the long-run response of policy to the output gap and inflation is larger than the original Taylor rule response of 0.5 . However, the estimate of the policy smoothing parameter is 0.62 in the time-varying model, similar to estimates obtained by English, Nelson, and Sack (2003), and considerably lower than the estimate of 0.91 obtained for the constant model. Estimates of transitory policy shocks are somewhat smaller in the time-varying target model than in the constant target model, suggesting that time-variation in the target and the funds rate natural rate explains some of the variation in the funds rate. Replacing the time-varying target and perceived target series, the constant model has a constant and credible inflation target, $\bar{\pi}$, estimated to be 4 percent.

Some of the persistence of inflation and nominal interest rates in the constant model is absorbed by low frequency fluctuations of the perceived inflation target in the natural rates of the time-varying model. Comparing estimates of coefficients in $\beta(L)$ in the time-varying model in Table 2 to those for the constant model in Table 3, reveals that the sum of coefficients on own lags is considerably lower in the time-varying model. The sum of coefficients on lags of long-term interest rates in the long rate equation is 0.66 , in the time-varying model and 0.78 in the constant model; The sum of coefficients on lags of inflation in the inflation equation is 0.53 in the time-varying model and 0.94 in the constant model. The next section will show that estimates of lower persistence of devatiations of economic variables from their natural rates in the time-varying model will show up as less persistent impulse functions.

The lower sum of coefficients in the time-varying target model in conjunction with the low frequency movements in the estimated perceived target series may help explain time-variation in the persistence of inflation as found by Kozicki and Tinsley (2002) and Cogley and Sargent (2003). In particular, the persistence of inflation incorporates the degree 
of persistence of inflation deviations as well as persistence in movements of the perceived inflation target. Thus, in small samples, estimates of persistence will tend to be close to the persistence of inflation deviations during periods when fluctuations in the perceived inflation target are small, such as 1986-1994, or 1997-2001. However, in periods with large movements in the perceived inflation target, such as 1966-1982, estimates of inflation persistence will be larger as they will be influenced by low frequency movements in the perceived inflation target.

The estimated transition equation for the implicit target found significant evidence of partial accommodation of supply shocks on the part of policymakers. The estimate of $c_{S T}$ implies that on average about $3 / 4$ of each supply shock was accommodated by policy. It should be noted that this estimate implies accommodation of adverse supply shocks such as higher oil or import prices and negative productivity shocks that would tend to raise inflation, as well as of supply shocks that would tend to lower inflation.

As expected, coefficient estimates of the Volker regime change parameter $\eta$ are negative and imply that the implicit target was reduced by 4.5 percentage points between 1979Q4 and 1982Q4. The coefficient estimate is insignificant, but based on only a few observations. The variance of exogenous permanent target shocks and the variance of expectations shocks were constrained to be equal. In the absence of this restriction, the standard errors of these parameter estimates were large. The restricted estimates imply that exogenous target shocks and exogenous expectations shocks tend to be relative small, with a standard deviation of $\sigma_{T}=\sigma_{P}=0.21$

The estimated learning parameter, $\delta$, is significant and implies that 8 percent of policy forecast errors are mapped into perceived target shifts. With an estimated policy response to inflation of 0.53 , roughly 4 percent of the gap between the target and perceived target is closed each quarter. This relatively slow learning rate implies lengthy lags between movements of the inflation target and the perceived target. 
The estimated actual and perceived target series exhibit considerable time variation and the difference between the two series can be sizable. In Figure 1, the estimates of the target and perceived target are predictions conditional on data through the previous period, but given estimates of model parameters based on the full sample. Movements in the estimated target reflect the direct contribution of permanent policy shocks to inflation variability. Thus, the figure suggests that permanent policy shocks that led to shifts in the implicit inflation target contributed importantly to fluctuations in the perceived target and inflation. This is a different view than Orphanides and Williams (2003) who assume that all variation in perceived target shifts is due to learning behavior. The sizable differences between movements in the actual target and the perceived target provide evidence that imperfect credibility associated with learning is also an important factor explaining time variation in the perceived target and inflation. Learning behavior introduces recognition lags so that movements of the perceived target lag those in the target series.

Also included in Figure 1 is a line reflecting the estimate of the constant target from the constant model. At 4 percent, the estimated constant target seems high for the recent period, while values of the estimated time-varying target are plausible. Describing his preference for an inflation target range, Governor Gramlich (2003) recently commented that he "would personally set the bottom of the range at slightly above 1 percent per year for the core $\mathrm{PCE}$ deflator,... and $\ldots$ the top of the range at about 2.5 percent per year. The midpoint of this range is then slightly less than 2 percent per year, which turns out to be about what U.S. core PCE inflation has averaged over the past eight years." The inflation goal of U.S. monetary policy is usually described as "price stability," Governor Bernanke (2003) provided his view of this concept, noting: "Inflation breached the 2 percent barrier in the spring of 1996 and has remained consistently within the narrow range of 1.5 to 2 percent for the past six and a half years-for practical purposes, a good approximation to price stability." 
Estimates of the target series, the real federal funds rate, and inflation are shown in Figure 2. The implicit target follows the same general low frequency movements observed in inflation and is similar to the "core" inflation series estimated by Cogley and Sargent (2003) and to the probability of a high inflation regime under asymmetric information in Schorfheide (2003). ${ }^{6}$ As would be expected, movements in the target generally lead movements in inflation. One exception to this leading property is the rapid rise in inflation in the mid-1970 that followed the first oil price shock. One interpretation is that the large increase in inflation at that time was a consequence of a negative supply shock and not due to a change in the inflation target. The subsequent increase in the estimated implicit target may then be interpreted as partial accommodation of the effects of the supply shock on inflation due to a reluctance on the part of the central bank to tighten policy as necessary to reverse this increase. This view is consistent with Bernanke (2003) who commented that "without Fed accommodation, higher oil prices abroad would not have translated into domestic inflation to any significant degree."

Also apparent in Figure 2 is a strong negative relationship between the real funds rate and the estimated implicit target. During the 1960s, the real funds rate fluctuated around about 2 percent and the estimated target inched upward. The target rose more rapidly in the late 1960s with the fall in the real funds rate. Subsequently, the negative real rates observed in the mid to late 1970s suggest that the Fed may have been willing to accept higher inflation. This policy shows up as a relatively high implicit inflation target. The policy was rapidly reversed with the Volker tightening. In the early 1980s a sizable reduction in the estimated implicit target is accompanied by a rapid rise in the real funds rate. Although the implicit target remained close to 4 percent through the "credit crunch" of the early 1990s, it has since fallen further.

\footnotetext{
${ }^{6}$ The probability of a high inflation regime under asymmetric information in Schorfheide (2003) increases somewhat later than the rise in the core inflation series of Cogley and Sargent (2003) and the increase in the inflation target estimated in the current paper.
} 
Estimates of the perceived inflation target series are shown in Figure 3 with inflation and long-term inflation expectations data from the Survey of Professional Forecasters. Movements in the perceived target tend to lag inflation, but track survey data on long-term inflation expectations quite well. The survey evidence provides independent support for the timing of movements in the perceived inflation target. Some differences between the perceived target series and the long-term inflation expectations series are to be expected. The long-term inflation expectations series is from a survey of expectations of inflation over the next 10 years while the perceived target is a limit of expectations. Also, the inflation series and estimated perceived target series are for inflation rates based on the chain price index for core personal consumption expenditures, while the long-term inflation expectations series is for inflation rates based on the consumer price index.

A notable feature of the estimated perceived target series is that the perceived target remains above inflation for much of the early- to mid-1980s and also in the 1990s. One interpretation is that in October 1979, when the FOMC undertook a change in policy to lower inflation, the private sector did not immediately see the new policy as fully credible. The perceived inflation target and long-term interest rates remained elevated despite declines in inflation in the early to mid 1980s. Only as policy was set to keep inflation low, did the perceived inflation target gradually recede towards the actual inflation rate.

The behavior of the estimated perceived inflation target in the 1980s may provide new insight on a debate between empirical and theoretical macroeconomic research. Theoretical macro models generally assume rational forward-looking behavior. By contrast, empirical researchers often opt for backward-looking assumptions in order to explain empirical regularities (Rudebusch (1998)). Comparing the estimated perceived target to inflation suggests an alternative view. In particular, if movements in the perceived inflation target lag movements in actual inflation, then rational forward-looking behavior on the part of 
agents may be misperceived as backward looking behavior. The lag may not be due to "irrationality" but to asymmetric information on the part of market participants and the Federal Reserve.

The model decomposes fluctuations in inflation and long-term rates into components due to natural rate movements and to transitory variation. As discussed earlier, in the time-varying target model, both permanent policy shocks and effects of learning associated with imperfect policy credibility contributed importantly to fluctuations in the perceived inflation target and inflation. Unlike the constant target model, natural rate movements in the time-varying target model also contribute importantly to fluctuations in long-term interest rates (Figure 4). Since the natural real rate and the term premium natural rate are both assumed to be constant, all the variation in the long-rate natural rate comes from variation in the perceived inflation target. Fluctuations in the long-rate natural rate are related to the level factor in Kozicki and Tinsley (2001b), Dewachter and Lyrio (2002), Hördahl, Tristani, and Vestin (2002) and Rudebusch and Wu (2003). Although quarter-to-quarter fluctuations in the natural rate are generally the same or smaller than those in long rate deviations, low frequency fluctuations involve swings that are as large. The main point to take from this chart is that variation in natural rates appears to be as important in contributing to historical movements in long rates as transitory variations around natural rates.

\section{Model Dynamics}

This section compares the dynamic properties of the time-varying target model to those of the constant-target model. The time-varying target model is used also to investigate the transition to a new inflation rate following a permanent policy shock to the inflation target and to examine behavior following an expectations shock, i.e., a shock to the perceived target. 
The two models have similar qualitative responses to aggregate demand shocks, transitory policy shocks and term premium shocks, but responses to the former two shocks tend to be more persistent and larger in the constant target model. However, model responses to aggregate supply shocks are considerably different as aggregate supply shocks lead to target shifts in the time-varying model. Figures 5 through 8 show responses of the two models to an aggregate demand shock, an aggregate supply (or cost push) shock, a term premium shock, and a transitory policy shock, respectively. Responses for the model with time-varying targets and asymmetric information are shown as the solid line in the Figures and labeled time-varying. The short dashed lines labeled constant show responses for the model with a known constant inflation target.

In response to a positive aggregate demand shock (Figure 5), the output gap, the long-term interest rate and the funds rate increase immediately. Inflation increases substantially in the constant model, but remains under control in the the time-varying model. The muted response of inflation in the time-varying model may reflect that with lags in inflation, policy can effectively cut off the adverse consequences of an aggregate demand shock before inflation responds. Furthermore, because policy actions are fully anticipated in the time-varying model, long-term inflation expectations are firmly anchored by a perceived inflation target that does shift with the demand shock. Because of the larger inflation response, the policy response is much more prolonged in the constant model and long-term interest rates remain elevated for a considerable period of time. In both models tighter monetary policy successfully slows output. In the long run, all variables return to their initial levels.

A positive aggregate supply shock (Figure 6) leads to an immediate increase in inflation. Responses to the shock differ considerably in the two models, however. In the constant model, the aggregate supply shock leads to an output contraction. The federal funds rate increases as the response to higher inflation dominates the response to weaker economic 
activity. In the long-run, all variables return to their initial levels. In the time-varying model, monetary policy partially accommodates the increase in inflation due to the supply shock by allowing the inflation target to increase. The output gap turns negative in the near-term as a consequence of the supply shock. Policy eases to avoid the negative output response as occurs in the model with the constant target. The easier policy reverses the negative output effect. Inflation, the federal funds rate, and the long-term interest rate gradually approach a new higher level as the private sector learns about the new higher target. The level to which they converge is 0.77 times the size of the initial shock.

Responses to term premium shocks are shown in Figure 7. This shock behaves like a liquidity demand shock. In particular, the shock may reflect the implications of an increased demand for funds on the part of producers who anticipate a future increase in sales. The rise in long-term interest rates correctly precedes the increase in output, which also leads to a tightening of policy. By this interpretation, the term premium shock act as a sales expectations shock or a credit demand shock.

Figure 8 shows the impulse responses to a transitory policy shock. Responses are less persistent in the time-varying model. The higher smoothing parameter in the estimated policy rule of the constant model leads to a more gradual reversal of the initial policy shock. In both models, tighter monetary policy leads to weaker economic activity, followed by a decline in inflation. The long-term interest rate is higher in the short run, reflecting the immediate increase in the funds rate. With weaker activity and lower inflation, policy eases and the long rate also declines below initial levels (again only slightly).

The response of inflation to a transitory policy shock exhibits a price puzzle in the constant model, but not in the time-varying model. This is partially explained by the downward adjustment of the perceived target in response to the policy shock. Not knowing with certainty whether the tighter policy is due to a transitory shock or a reduction in the inflation target, private sector agents put some weight on the latter possibility and the 
perceived inflation target moves down. In the long-run, all variables return to their initial levels in both models. In the time-varying model, agents correctly learn that the policy shock was only transitory.

The final two simulations examine responses to permanent target shocks and to expectations shocks. These experiments could only be run in the time-varying target model because in the other model the target and perceived target are constrained to be constant. Figure 9 reports impulse responses to a permanent target shock that increases the inflation target by one percentage point. Policy immediately eases strongly, because with the increase in the target, inflation is now too low. In the absence of an immediate inflation response, the lower nominal funds rate implies a lower real funds rate and leads to a small decline in long-term rates and to an expansion of output. Unexpectedly easy policy leads private sector agents gradually to believe that the inflation target may be higher and the perceived inflation target increases. Inflation increases with higher aggregate demand and the increase in the perceived target. Initially, the increase in the perceived target leads the increase in inflation. As inflation increases towards the target, policy becomes less expansionary. Eventually the output gap returns to zero. However, the perceived target gradually converges towards the new inflation target as does inflation. The long-term interest rate and the federal funds rate also fully incorporate the permanent increase in inflation and converge to a level that is one percentage point higher than initially.

Responses to a shock to the perceived target are shown in Figure 10. This expectational shock occurs in the absence of a change in the target. Output increases initially because an increase in the perceived target in the absence of an increase in inflation is like a reduction in inflationary pressures which stimulates aggregate demand. Excess demand then leads to rising inflation. The funds rate is increased to bring down inflation and higher inflation, and the long rate follows suit. With tighter policy the economic activity slows, and inflation declines. Tighter than expected policy leads private sector agents to revise down their 
perception of the inflation target. Gradually, all variables return to their pre-shock levels.

\section{Impulse response tradeoffs associated with different learning rates}

The estimated learning function in the time-varying target model implies very slow learning about the target shift. In Figure 9, it takes 16 quarters for the perceived target to move half way to the new target. To gain insight about the effects of improved credibility with faster learning, the estimated learning parameter $\delta=0.079$ was increased by two standard errors to 0.157 to simulate the implications of faster learning:

$$
\pi^{P}(t+1)=\pi^{P}(t)-0.157\left[r_{t}-r_{t}^{e}\right]+u_{P, t}
$$

Impulse responses were recalculated assuming all other aspects of the model would be unaffected. ${ }^{7}$

Responses to the transitory policy shock show how faster learning can lead to excess volatility in steady states. Here, a steady state corresponds to a policy regime with a constant inflation target. With the inflation target unchanged, faster learning implies that variables return to unchanged natural rates more quickly. However, as shown in Figure 11, with faster learning, responses to a transitory policy shock are more volatile. The higher volatility reflects that the immediate response of the perceived target to the transitory policy shock is larger under faster learning.

With faster learning, the total real effects associated with transition to a new policy regime are smaller. Figure 12 shows responses to a permanent target shock. The perceived target adjusts halfway to the new target in 8 quarters and 3/4 of the way in 16 quarters-the time it took to adjust halfway with the slower estimated learning parameter. Total real effects can be measured as the integral between the impulse response of the output gap and

\footnotetext{
${ }^{7}$ This ceteris paribus is a simplifying assumption and may not hold in a general analysis containing a model of endogenous learning.
} 
zero. For the first 50 simulated quarters, the cumulated real output cost is 15.68 in the response of the estimated model (also shown in Figure 9) and is 8.93 in the response of the faster learning model.

Overall, these simulations illustrate that with faster learning, nominal variables approach their natural rate much more rapidly, total real effects of shocks are smaller, but the volatility of responses to transitory policy shocks is larger. However, the results suggest that excess volatility that occurs in the absence of permanent target shocks may be reduced by allowing the learning parameter to vary over time. One approach is to assume aggregation across heterogeneous expectations differentiated by learning speed. Time variation of the aggregate learning parameter could reflect different weightings across alternative constant-gain learners. In the current model, target shocks, whether from accommodation of supply shocks or from exogenous sources, are assumed to be homoskedastic. In a more general specification, target shocks might be viewed as heteroskedastic, either due to heteroskedasticity in the underlying structural shocks or to a change in the parameter governing the accommodation of aggregate supply shocks. With heteroskedastic target shocks, a larger fraction of learners may choose to use fast learning when the size of recent policy forecast errors increases and slow learning when the size of policy forecast errors decreases. Such time-varying aggregation may be accomplished using multinomial logit techniques as in Kozicki and Tinsley (2001a) or Branch (2003).

\section{Final Remarks}

This paper proposes an empirical model fit to U.S. data, with permanent and transitory policy shocks and asymmetric policy information. The model incorporates a possibly time-varying inflation target and a time-varying perceived inflation target. The perceived inflation target may differ from the actual target because private agents are assumed to not observe the true target and must learn whether movements in the federal funds 
rate are due to transitory policy shocks or to permanent policy shocks that change the inflation target. Deviations between the estimated actual and perceived target provide evidence of asymmetric information on the part of private sector agents about the inflation goal of monetary policy. The results suggest that time-varying natural rates associated with movements in the perceived inflation target contributed importantly to historical fluctuations in inflation and long-term interest rates. Both permanent policy shocks and learning associated with imperfect policy credibility explain movements in the perceived inflation target.

In the perpetual learning model of the inflation target, the perceived inflation target is adjusted to reflect deviations of funds rate settings from predictions conditioned on the perceived inflation target. Although the estimated speed of learning is quite slow-with only 4 percent of the gap between the target and the perceived target closed per quarter-implied model dynamics and interactions between variables appeared reasonable. Learning behavior implies lengthy lags between movements in the actual inflation target and the perceived inflation target. The estimated perceived inflation target tracks movements in long-horizon survey expectations of inflation quite well. Important dynamic features of the model are the absence of a price puzzle in the response to a transitory policy shock and permanent nominal effects of aggregate supply shocks due to partial policy accommodation. In contrast to standard VARs, the specification can be used to examine the dynamic responses to a permanent change in the inflation target and to expectations shocks.

Finally, the paper uses simulations to show that faster learning associated with increased credibility could shorten the transition period to a new inflation target, and reduce the real effects associated with such a policy change. However, faster learning also implies greater volatility in response to transitory policy shocks. 


\section{References}

Andolfatto, David and Paul Gomme, 2003, "Monetary Policy Regimes and Beliefs," International Eocnomic Review, 44, 1-30.

Bernanke, Ben S., 2003, " 'Constrained Discretion' and Monetary Policy," remarks before the Money Marketeers of New York University, New York, New York, February 3, 2003.

Bernanke, Ben S., Mark Gertler, and Mark Watson, 1997, "Systematic Monetary Policy and the Effects of Oil Price Shocks," Brookings Papers on Economic Activity:1, 91-142.

Branch, William A., 2003, "The Theory of Rationally Heterogeneous Expectations: Evidence from Survey Data on Inflation Expectations," Manuscript, College of William and Mary.

Brunner, Allan D., 1991, "Testing for Structural Breaks in U.S. Post-War Inflation," Unpublished manuscript, Division of Monetary Affairs, Board of Governors of the Federal Reserve System, Washington D.C.

Bullard, James and In-Koo Cho, 2002, "Escapist Policy Rules," Federal Reserve Bank of St. Louis Working Paper 2002-002A.

Bullard, James and John Duffy, 2003, "Learning and Structural Change in Macroeconomic Data," manuscript, Federal Reserve Bank of St. Louis, March.

Bullard, James and S. Eusepi, 2003, "Did the Great Inflation Occur Despite Policymaker Commitment to a Taylor Rule," June.

Clarida, Richard, Jordi Gali, and Mark Gertler, 1998, "Monetary Policy Rules in Practice: Some International Evidence," European Economic Review, 42, 1033-1067.

Cogley, Timothy, and Thomas J. Sargent, 2003, "Drifts and Volatilities: Monetary Policies and Outcomes in the Post WWII U.S.," manuscript.

Cukierman, Alex and Allan H. Meltzer, 1986, "A Theory of Ambiguity, Credibility, and Inflation under Discretion and Asymmetric Information," Econometrica, 54, 1099-1128.

DeWachter, Hans, and Marco Lyrio, 2002, "Macro Factors and the Term Structure of Interest Rates," manuscript, Catholic University of Leuven.

English, William B., William R. Nelson, and Brian P. Sack, 2003, "Interpreting the Significance of the Lagged Interest Rate in Estimated Monetary Policy Rules," Contributions to Macroeconomics, 3.

Erceg, Chrishtoper J. and Andrew T. Levin, 2003, "Imperfect Credibility and Inflation 
Persistence," Journal of Monetary Economics, 50, 915-944.

Evans, Martin D.D. and Paul Wachtel, 1993, "Inflation Regimes and the Sources of Inflation Uncertainty," Journal of Money, Credit, and Banking, 25, 475-511.

Evans, Martin D.D. and Karen K. Lewis, 1995, "Do Expected Shifts in Inflation affect Estimates of the Long-run Fisher Relation," The Journal of Finance, 50, 225-253.

Evans, George W., and Seppo Honkapohja, 2001, Learning and Expectations in Macroeconomics. Princeton: Princeton University Press.

Evans, George W., and Seppo Honkapohja, 2003, "Learning with Bounded Memory in Stochastic Models," Journal of Economic Dynamics and Control, 1437-57.

Fuhrer, Jeffrey C., 1996, "Monetary Policy Shifts and Long-Term Interest Rates," Quarterly Journal of Economics, 111, 1183-1209.

Garcia, R. and P. Perron, 1996, "An analysis of the real interest rate under regime shifts," Review of Economics and Statistics," 78, 111-125.

Gramlich, Edward M., 2003, "Maintaining Price Stability," remarks before the Economic Club of Toronto, Toronto, Canada, October 1, 2003.

Gürkaynak, Refet S., Brian Sack, and Eric Swanson, 2003, "The Excess Sensitivity of Long-term Interest Rates: Evidence and Implications for Macroeconomic Models," manuscript, Federal Reserve Board.

Hördahl, Peter, Oreste Tristani, and David Vestin, 2002, "A joint econometric model of macroeconomic dynamics and term structure dynamics," manuscript, European Central Bank.

Huh, Chan G. and Kevin J. Lansing, 2000, "Expectations, Credibility, and Disinflation in a Small Macroeconomic Model," Journal of Economics and Business, 51, 51-86.

Kozicki, Sharon, 1999, "How Useful are Taylor Rules for Monetary Policy?" Federal Reserve Bank of Kansas City Economic Review, Second Quarter, 5-33.

Kozicki, Sharon and Peter A. Tinsley, 2001a, "Term Structure Views of Monetary Policy under Alternative Models of Agent Expectations," Journal of Economic Dynamics and Control, 25, 149-184.

Kozicki, Sharon and Peter A. Tinsley, 2001b, "Shifting Endpoints in the Term Structure of Interest Rates," Journal of Monetary Economics, 47, 613-652.

Kozicki, Sharon and Peter A. Tinsley, 2001c, "What Do You Expect? Imperfect Policy Credibility and Tests of the Expectations Hypothesis," Federal Reserve Bank of Kansas City Working Paper 0102. 
Kozicki, Sharon and Peter A. Tinsley, 2002, "Alternative Sources of the Lag Dynamics of Inflation," Federal Reserve Bank of Kansas City Research Working Paper 02-12.

Levin, Andrew T. and Jeremy M. Piger, 2002, "Is Inflation Persistence Intrinsic in Industrial Economies?" manuscript.

Lucas, Robert E., 1973, "Some International Evidence on Output-Inflation Tradeoffs," American Economic Review, 63, 326-34.

Meyer, Laurence H., and Charles Webster, Jr., 1982, "Monetary Policy and Rational Expectations: A Comparison of Least Squares and Bayesian Learning," Carnegie-Rochester Conference Series on Public Policy, 17, 67-98.

Orphanides, Athanasios, and John C. Williams, 2003, "Imperfect Knowledge, Inflation Expectations, and Monetary Policy," NBER Working Paper 9884.

Rudebusch, Glenn, 1998, "Is the Fed too Timid? Monetary Policy in an Uncertain World," Federal Reserve Bank of San Francisco, manuscript.

Rudebusch, Glenn, and Lars E.O. Svensson, 1999, "Policy Rules for Inflation Targeting," in Monetary Policy Rules, ed. by John B. Taylor, A National Bureau of Economic Research Conference Report. Chicago: The University of Chicago Press, 203-259.

Rudebusch, Glenn, and Tao Wu, 2003, "A Macro-Finance Model of the Term Structure, Monetary Policy, and the Economy," manuscript, Federal Reserve Bank of San Francisco.

Sargent, Thomas J., 1993, Bounded Rationality in Macroeconomics. Oxford: Clarendon Press.

Sargent, Thomas J. and Neil Wallace, 1976, "Rational Expectations and the Theory of Economic Policy," Journal of Monetary Economics, 2, 193-228.

Schorfheide, Frank, 2003, "Learning and Monetary Policy Shifts," manuscript.

Taylor, John B., 1975, "Monetary Policy during a Transition to Rational Expectations," The Journal of Political Economy, 83, 1009-1022.

Taylor, John B., 1980, "Recent Developments in the Theory of Stabilization Policy," in Stabilization Policies: Lessons from the Seventies and Implications for the Eighties, ed. by Laurence Meyer, Center for the Study of American Business, Conference Volume No. 4. St. Louis: Federal Reserve Bank of St. Louis, 1-40.

Taylor, John B., 1993, "Discretion versus Policy in Practice," Carnegie-Rochester Conference Series on Public Policy,, 39, December, 195-214.

Taylor, John B., 1999, Monetary Policy Rules. Chicago: University of Chicago Press. 
Tetlow, Robert J. and Peter von zur Muehlen, 2001, "Simplicity versus Optimality: The Choice of Monetary Policy Rules when Agents Must Learn," Journal of Economic Dynamics and Control, 25, 245-279. 
Table 1: Estimation Results

\begin{tabular}{l|rc|rc}
\hline \hline & \multicolumn{2}{|c}{ Time-varying Model } & \multicolumn{2}{c}{ Constant Model } \\
Parameter & Estimate & Standard Error & Estimate & Standard Error \\
\hline $\bar{y}$ & -0.11 & 0.76 & -0.31 & 0.47 \\
$\bar{r}$ & 2.99 & 0.74 & 2.79 & 0.46 \\
$\bar{\theta}$ & 0.71 & 0.28 & 0.72 & 0.19 \\
$\gamma_{y}$ & 0.35 & 0.13 & 0.14 & 0.03 \\
$\gamma_{\pi}$ & 0.53 & 0.25 & 0.16 & 0.05 \\
$\rho$ & 0.62 & 0.10 & 0.91 & 0.03 \\
$\bar{\pi}$ & & & 4.00 & 0.73 \\
$\delta$ & 0.08 & 0.04 & & \\
$\eta$ & -0.35 & 0.26 & & \\
$c_{D S}$ & -0.01 & 0.16 & 0.07 & \\
$c_{D r}$ & & & 0.13 & \\
$c_{S r}$ & & & 0.21 & \\
$c_{D \tau}$ & 0.19 & 0.10 & 0.18 & \\
$c_{S \tau}$ & 0.14 & 0.06 & 0.17 & \\
$c_{r \tau}$ & 0.29 & 0.08 & 0.25 & \\
$c_{S T}$ & 0.77 & 0.34 & & \\
$\sigma_{D}$ & 0.68 & 0.05 & 0.67 & \\
$\sigma_{S}$ & 0.71 & 0.06 & 0.76 & \\
$\sigma_{r}$ & 0.76 & 0.07 & 0.93 & \\
$\sigma_{\tau}$ & 0.34 & 0.03 & 0.36 & \\
$\sigma_{T}=\sigma_{P}$ & 0.21 & 0.13 & & \\
\hline \hline
\end{tabular}

The time-varying model was estimated using maximum likelihood with Kalman filtering techniques to estimate the two unobserved state variables (the inflation target and the perceived inflation target). The constant model was estimated using a generalized version of the seemingly unrelated regression method that allows for cross-equation restrictions on parameters. Estimates of the coefficients that summarize the structural relationships between the residuals and estimates of the standard errors of the structural shocks are obtained using a Cholesky decomposition of the estimated residual covariance matrix. Estimates of the VAR slope coefficients in $\beta(L)$ are provided in Table 2 for the time-varying model and in Table 3 for the constant model. 
Table 2: Estimates of $\beta(L)$ for the Time-varying Model

\begin{tabular}{|c|c|c|c|c|c|c|c|}
\hline \multirow{3}{*}{$\begin{array}{l}\text { Deviation } \\
\text { Variable }\end{array}$} & \multirow{3}{*}{ lag } & \multicolumn{6}{|c|}{ Equation } \\
\hline & & \multicolumn{2}{|c|}{ Output gap } & \multicolumn{2}{|c|}{ Inflation } & \multicolumn{2}{|c|}{ Long rate } \\
\hline & & coef & S.E. & coef & S.E. & coef & S.E. \\
\hline \multirow[t]{4}{*}{ Output gap } & 1 & 1.05 & 0.10 & -0.01 & 0.14 & 0.10 & 0.09 \\
\hline & 2 & 0.03 & 0.16 & -0.07 & 0.18 & -0.05 & 0.11 \\
\hline & 3 & -0.14 & 0.15 & -0.06 & 0.18 & -0.06 & 0.10 \\
\hline & 4 & 0.01 & 0.12 & 0.17 & 0.11 & -0.03 & 0.09 \\
\hline \multirow[t]{4}{*}{ Inflation } & 1 & -0.12 & 0.12 & 0.60 & 0.14 & -0.16 & 0.07 \\
\hline & 2 & -0.04 & 0.13 & -0.11 & 0.12 & 0.05 & 0.08 \\
\hline & 3 & 0.03 & 0.14 & 0.06 & 0.13 & 0.04 & 0.09 \\
\hline & 4 & 0.05 & 0.11 & -0.02 & 0.12 & -0.08 & 0.08 \\
\hline \multirow[t]{4}{*}{ Funds rate } & 1 & 0.05 & 0.15 & 0.14 & 0.12 & 0.02 & 0.06 \\
\hline & 2 & -0.35 & 0.21 & -0.09 & 0.20 & 0.02 & 0.09 \\
\hline & 3 & 0.22 & 0.21 & 0.09 & 0.20 & 0.13 & 0.08 \\
\hline & 4 & -0.05 & 0.14 & -0.01 & 0.14 & 0.03 & 0.07 \\
\hline \multirow[t]{4}{*}{ Long Rate } & 1 & 0.02 & 0.28 & -0.33 & 0.25 & 0.91 & 0.07 \\
\hline & 2 & -0.06 & 0.34 & 0.37 & 0.33 & -0.05 & 0.17 \\
\hline & 3 & 0.23 & 0.32 & -0.14 & 0.38 & -0.09 & 0.18 \\
\hline & 4 & -0.13 & 0.25 & -0.18 & 0.24 & -0.11 & 0.10 \\
\hline
\end{tabular}


Table 3: Estimates of $\beta(L)$ for the Constant Model

\begin{tabular}{|c|c|c|c|c|c|c|c|}
\hline \multirow{3}{*}{$\begin{array}{l}\text { Deviation } \\
\text { Variable }\end{array}$} & \multirow{3}{*}{ lag } & \multicolumn{6}{|c|}{ Equation } \\
\hline & & \multicolumn{2}{|c|}{ Output gap } & \multicolumn{2}{|c|}{ Inflation } & \multicolumn{2}{|c|}{ Long rate } \\
\hline & & coef & S.E. & coef & S.E. & coef & S.E. \\
\hline \multirow[t]{4}{*}{ Output gap } & 1 & 1.04 & 0.08 & 0.03 & 0.09 & 0.09 & 0.05 \\
\hline & 2 & 0.01 & 0.11 & -0.03 & 0.12 & -0.03 & 0.07 \\
\hline & 3 & -0.12 & 0.11 & -0.04 & 0.12 & -0.03 & 0.06 \\
\hline & 4 & -0.01 & 0.08 & 0.12 & 0.09 & -0.04 & 0.05 \\
\hline \multirow[t]{4}{*}{ Inflation } & 1 & -0.08 & 0.07 & 0.78 & 0.08 & -0.04 & 0.04 \\
\hline & 2 & -0.03 & 0.09 & -0.04 & 0.10 & 0.07 & 0.06 \\
\hline & 3 & 0.05 & 0.09 & 0.11 & 0.11 & 0.07 & 0.06 \\
\hline & 4 & 0.06 & 0.07 & 0.09 & 0.08 & -0.01 & 0.04 \\
\hline \multirow[t]{4}{*}{ Funds rate } & 1 & 0.08 & 0.08 & 0.19 & 0.09 & 0.03 & 0.05 \\
\hline & 2 & -0.35 & 0.10 & -0.12 & 0.11 & -0.00 & 0.06 \\
\hline & 3 & 0.21 & 0.10 & 0.05 & 0.11 & 0.10 & 0.06 \\
\hline & 4 & -0.08 & 0.07 & -0.09 & 0.08 & -0.02 & 0.04 \\
\hline \multirow[t]{4}{*}{ Long Rate } & 1 & -0.00 & 0.15 & -0.24 & 0.16 & 0.96 & 0.09 \\
\hline & 2 & -0.04 & 0.20 & 0.28 & 0.23 & -0.09 & 0.12 \\
\hline & 3 & 0.22 & 0.21 & -0.13 & 0.24 & -0.07 & 0.13 \\
\hline & 4 & -0.13 & 0.14 & 0.09 & 0.16 & -0.02 & 0.08 \\
\hline
\end{tabular}


Figure 1: Time-Varying Inflation Target, Constant Inflation Target, Perceived Inflation Target, and Inflation

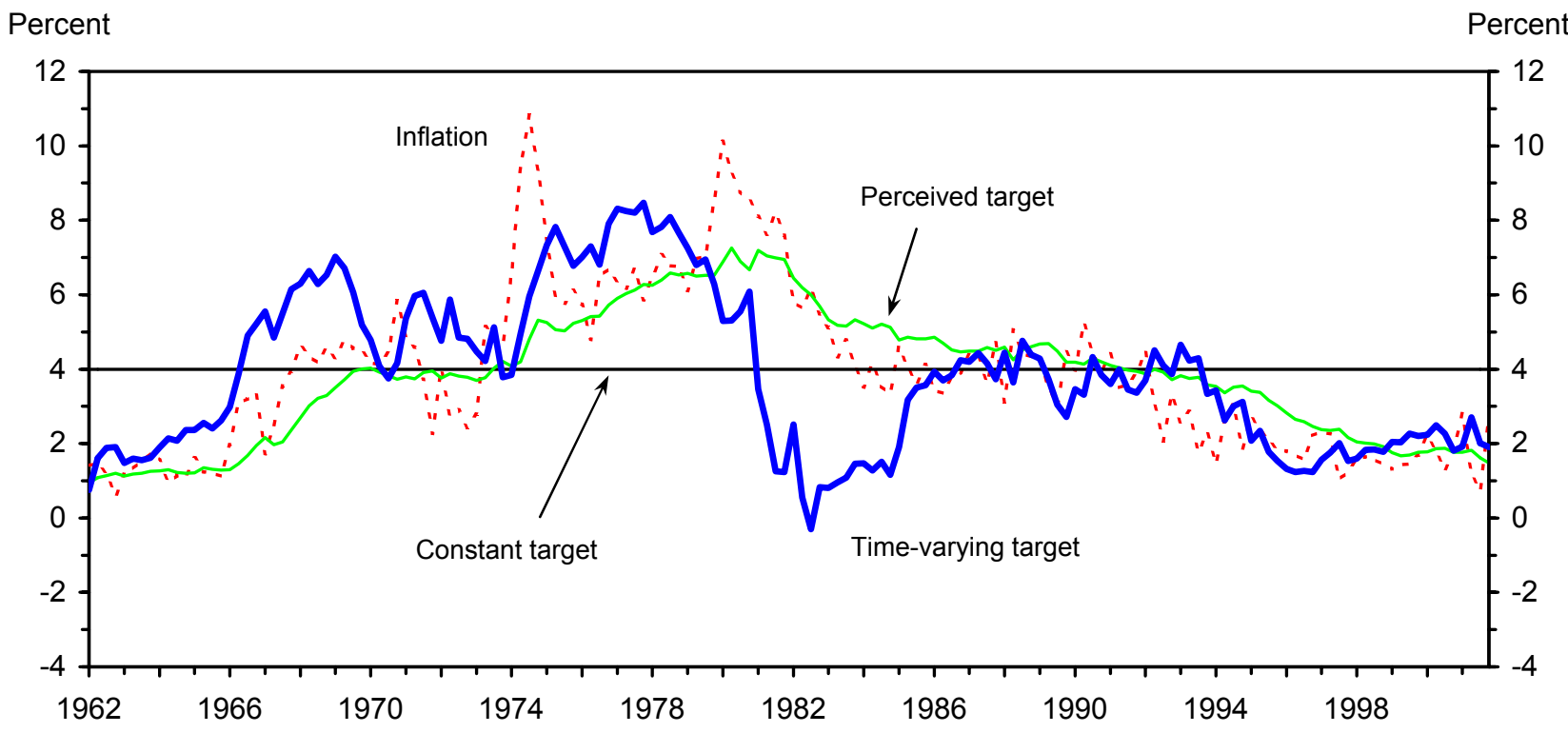

Figure 2: Inflation, the Real Fed Funds Rate, and the Estimated Inflation Target

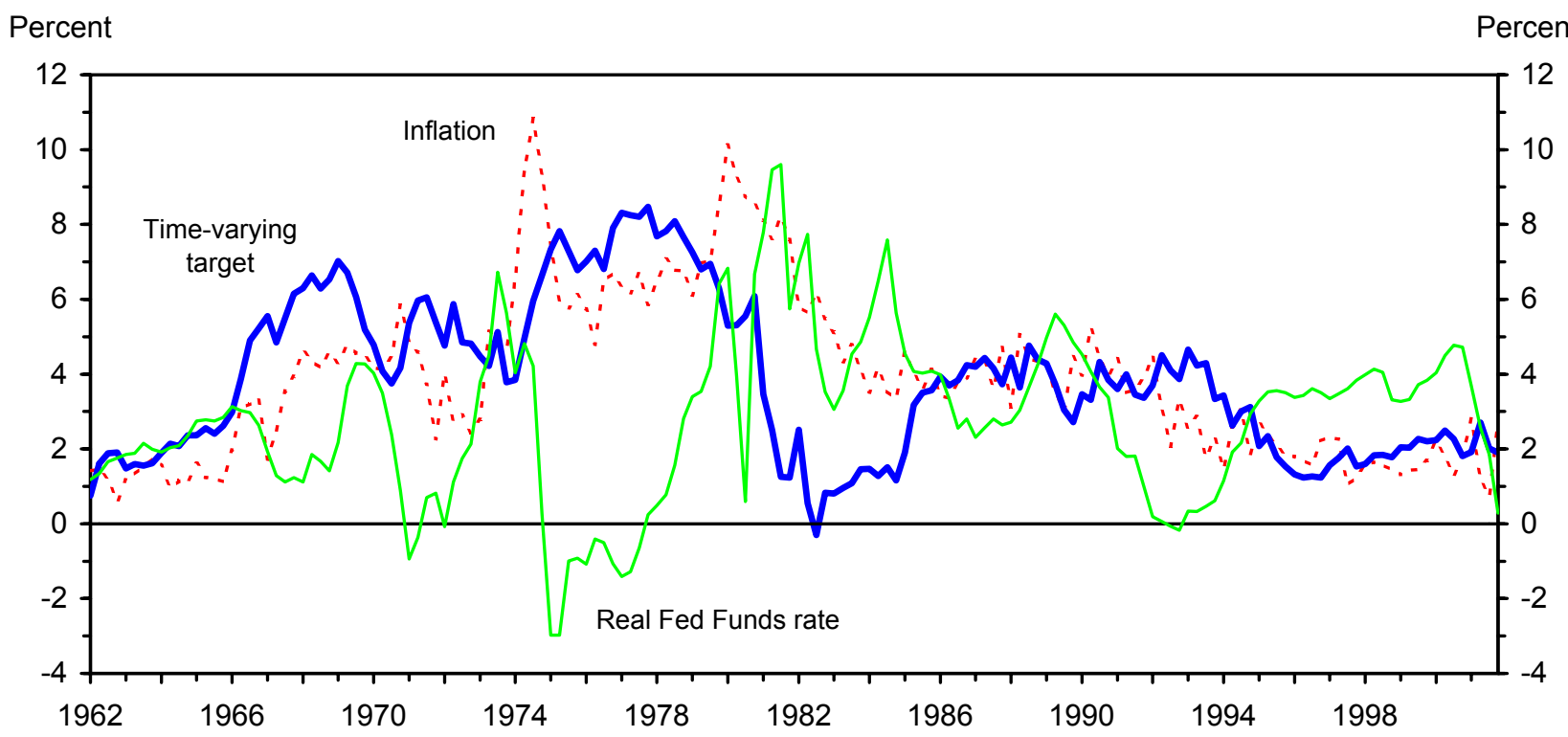


Figure 3: Inflation, the Estimated Perceived Inflation Target, and Long-Term Inflation Expectations

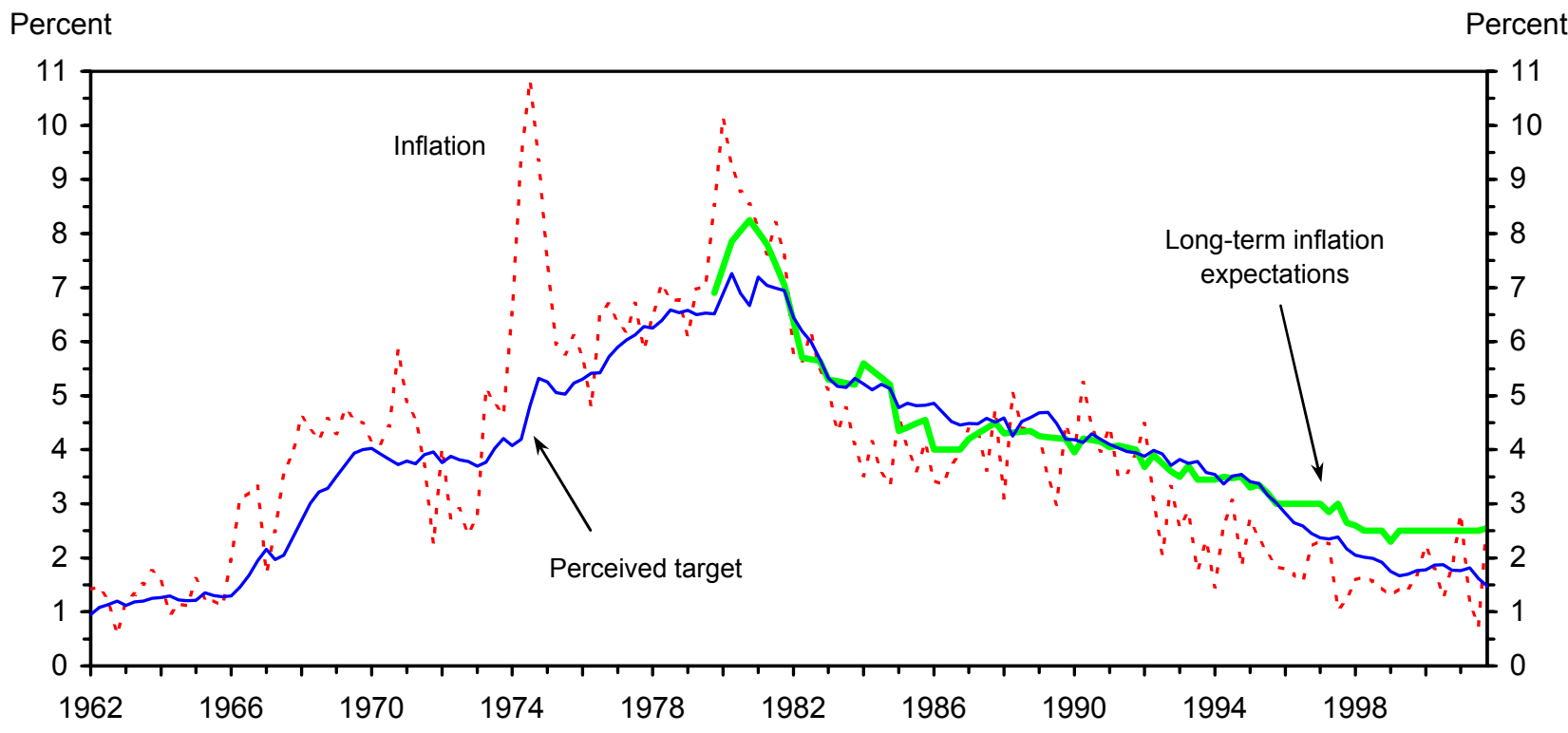

Figure 4: Time-Varying Natural Rate, Constant Natural Rate, and the Long-Term Interest Rate

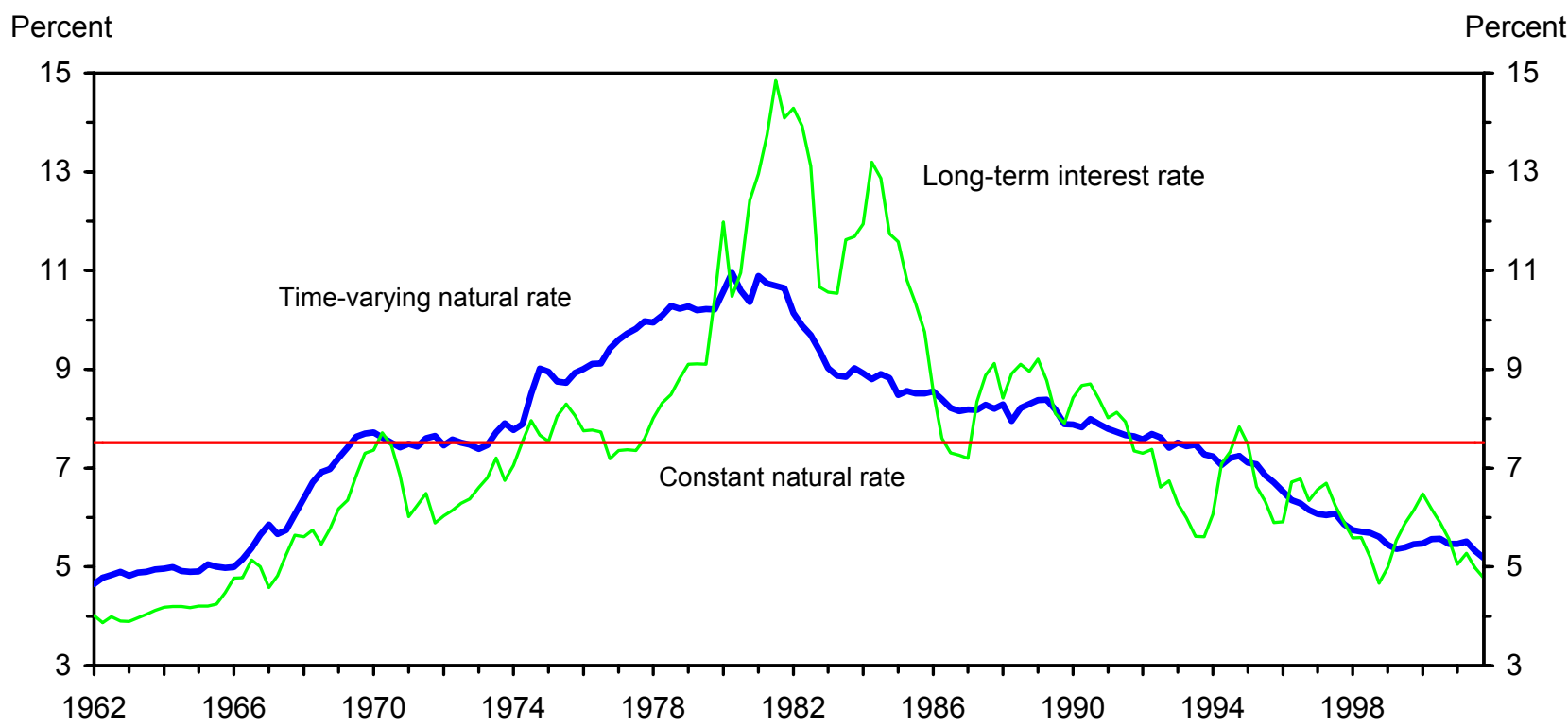


Figure 5: Impulse Responses to an Aggregate Demand Shock

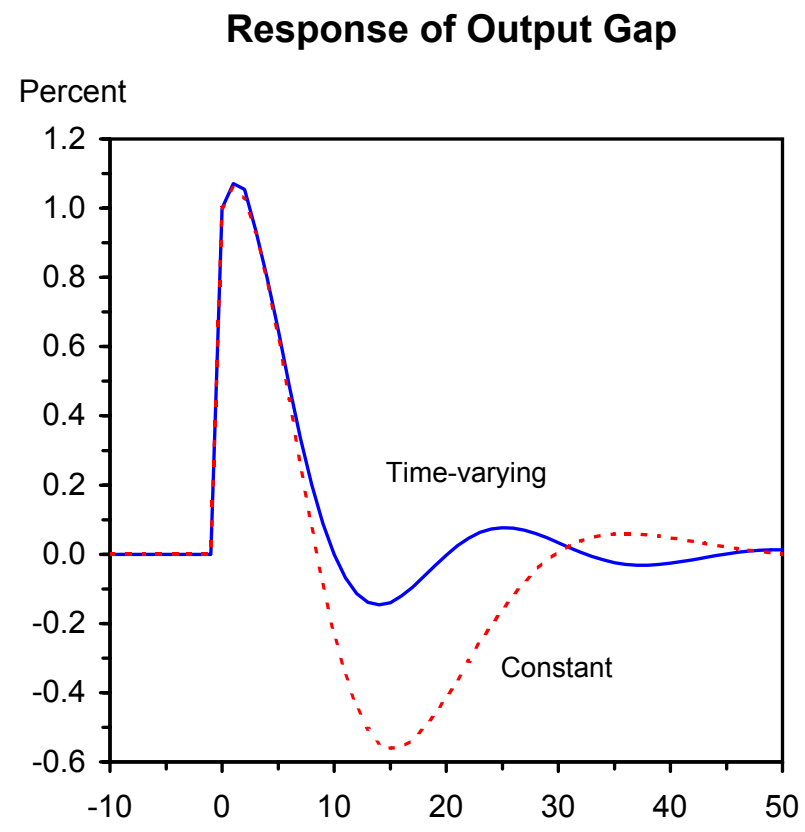

Response of Inflation

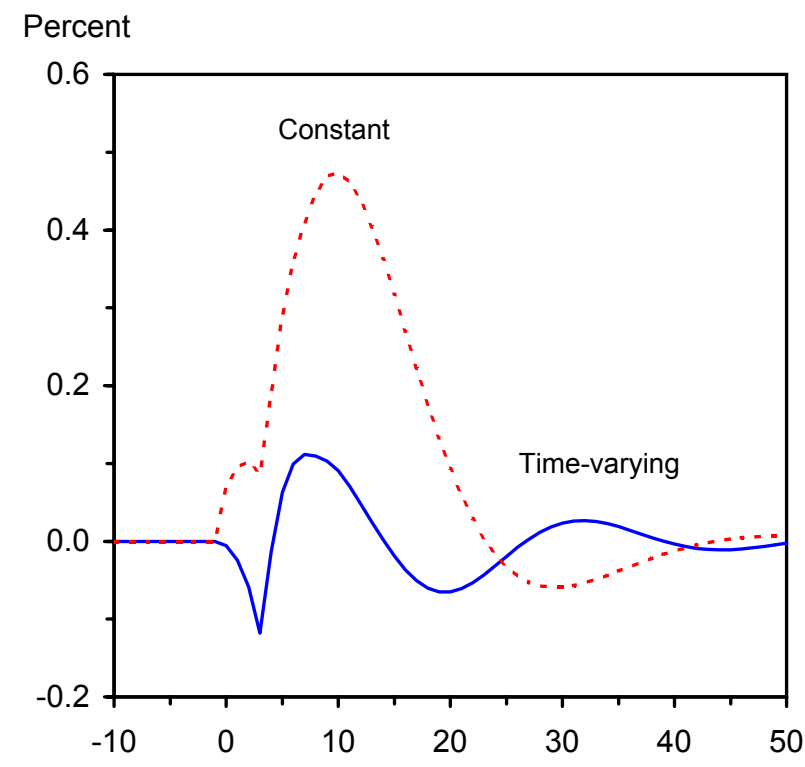

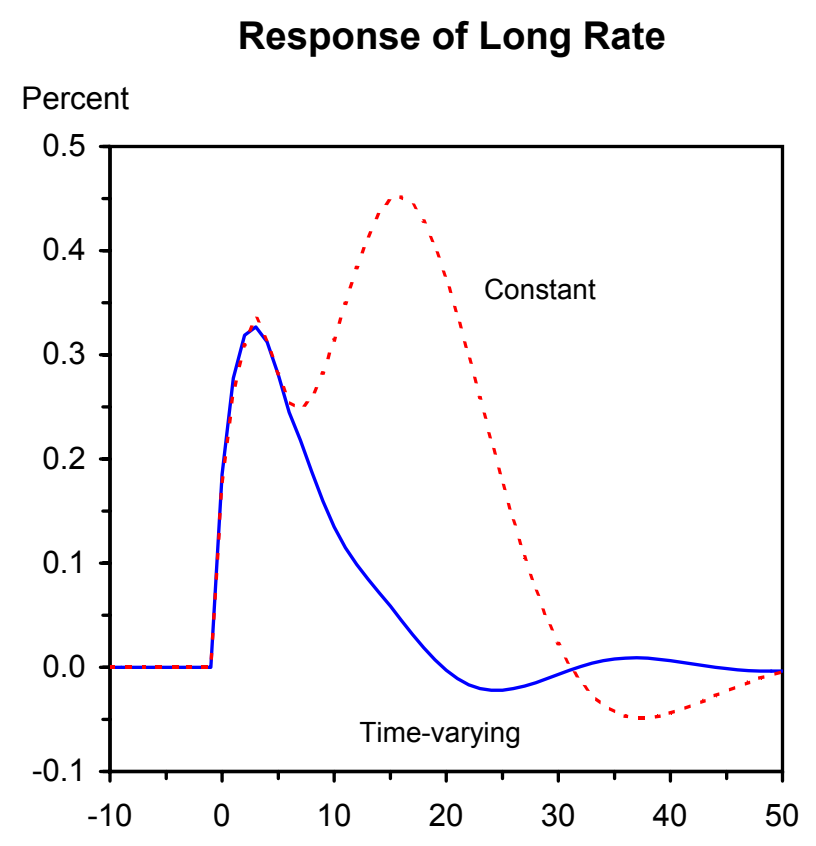

Response of Fed Funds Rate

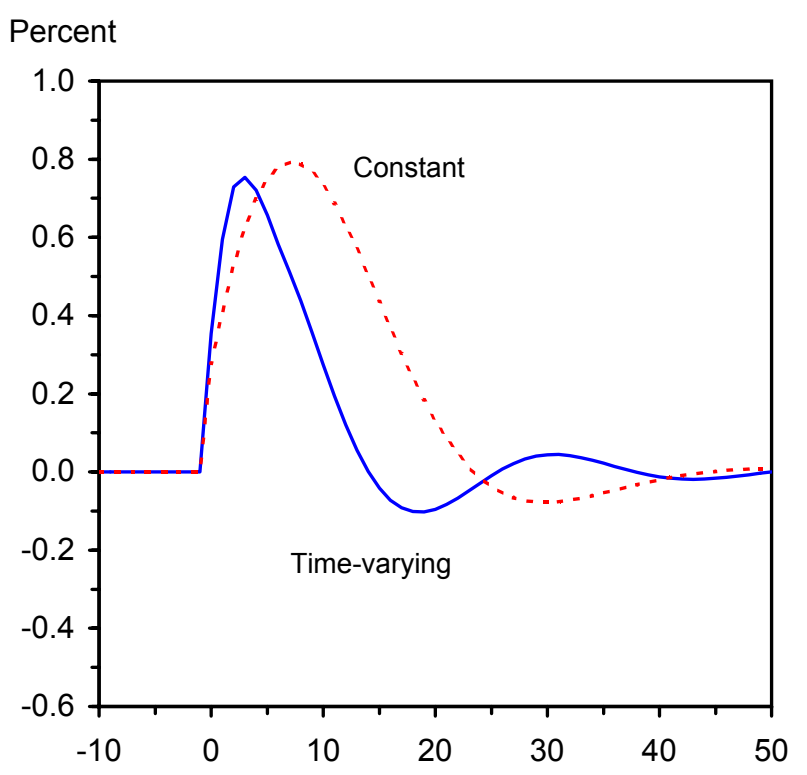


Figure 6: Impulse Responses to an Aggregate Supply Shock

\section{Response of Output Gap}

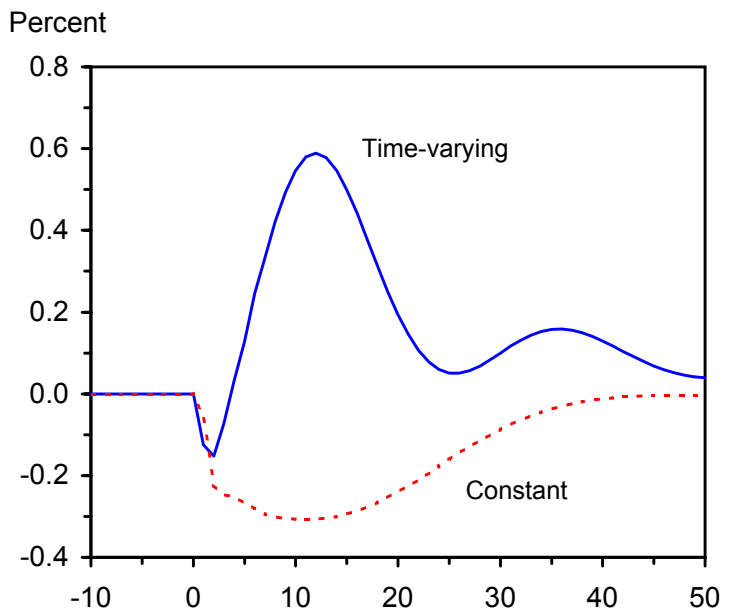

Response of Long Rate

Percent

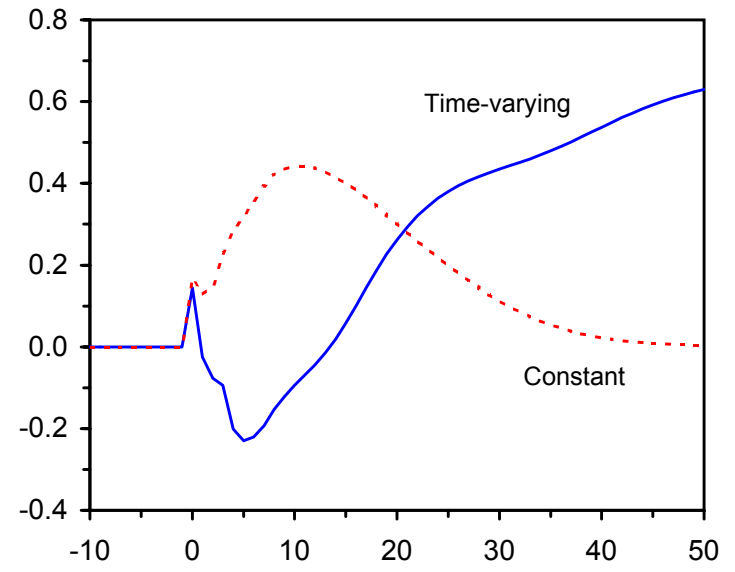

Response of Target

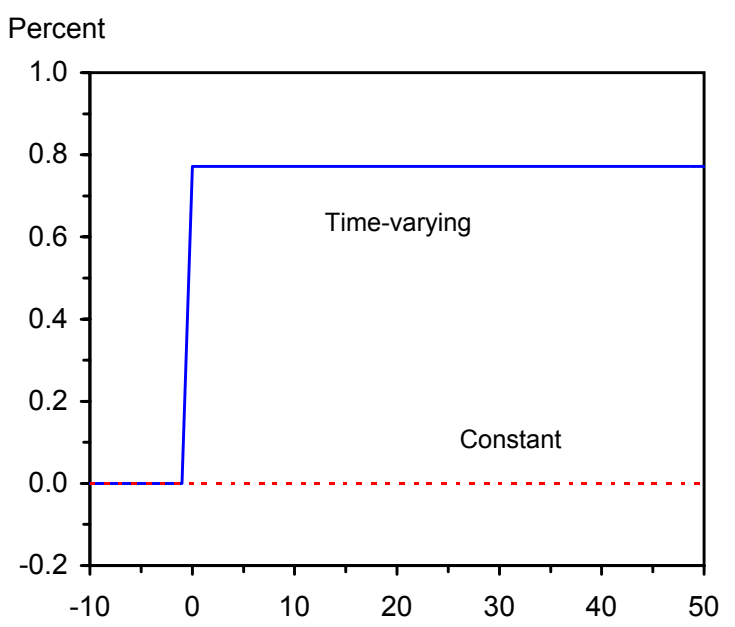

\section{Response of Inflation}

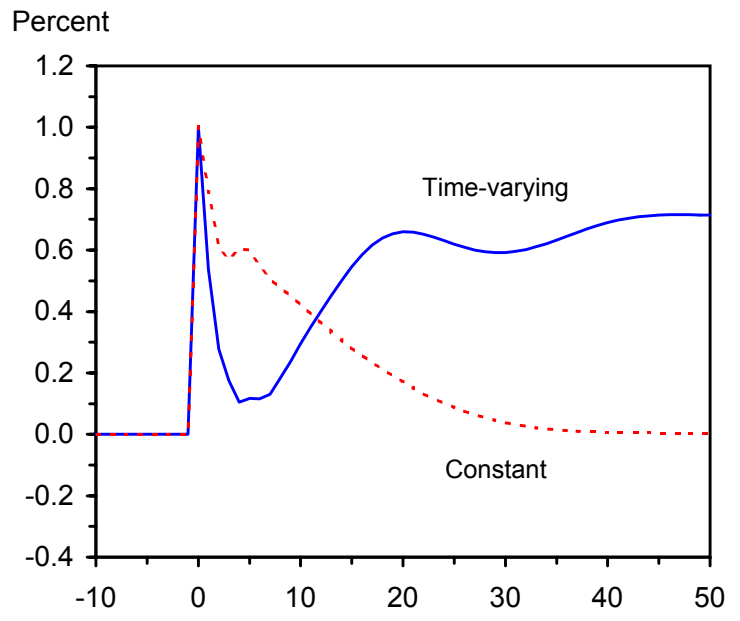

Response of Fed Funds Rate

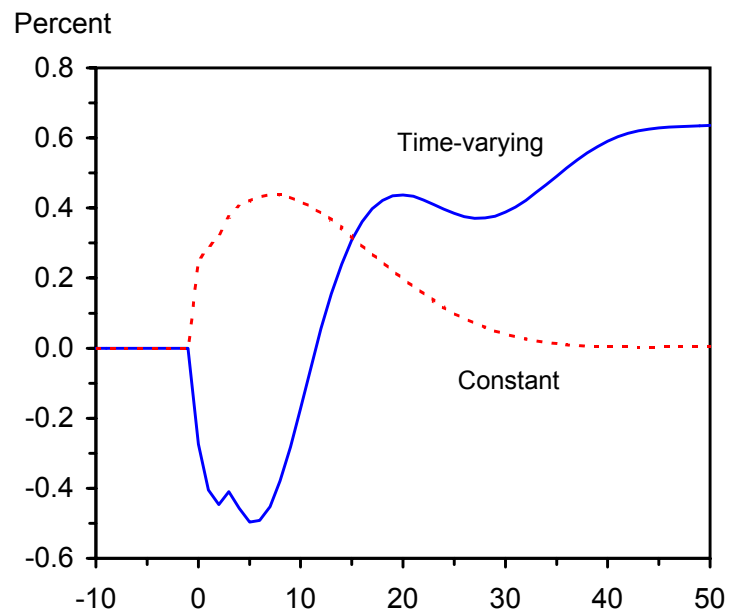

Response of Perceived Target

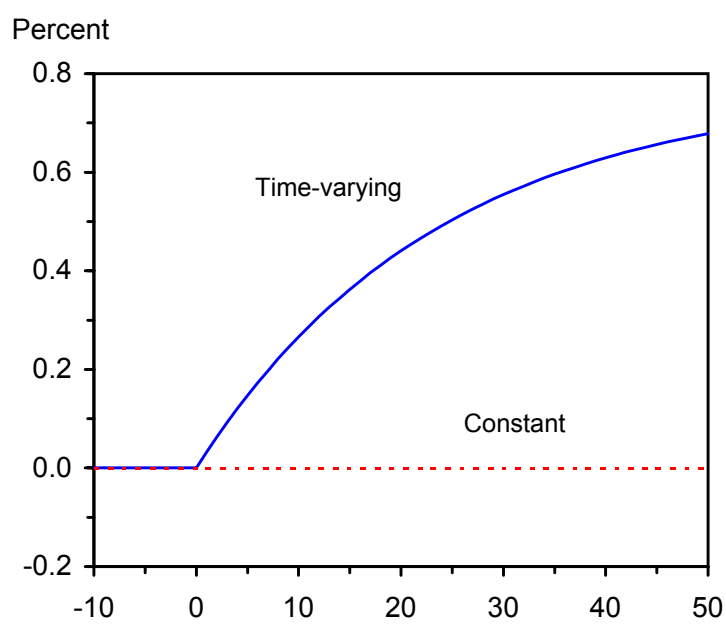


Figure 7: Impulse Responses to a Term Premium Shock
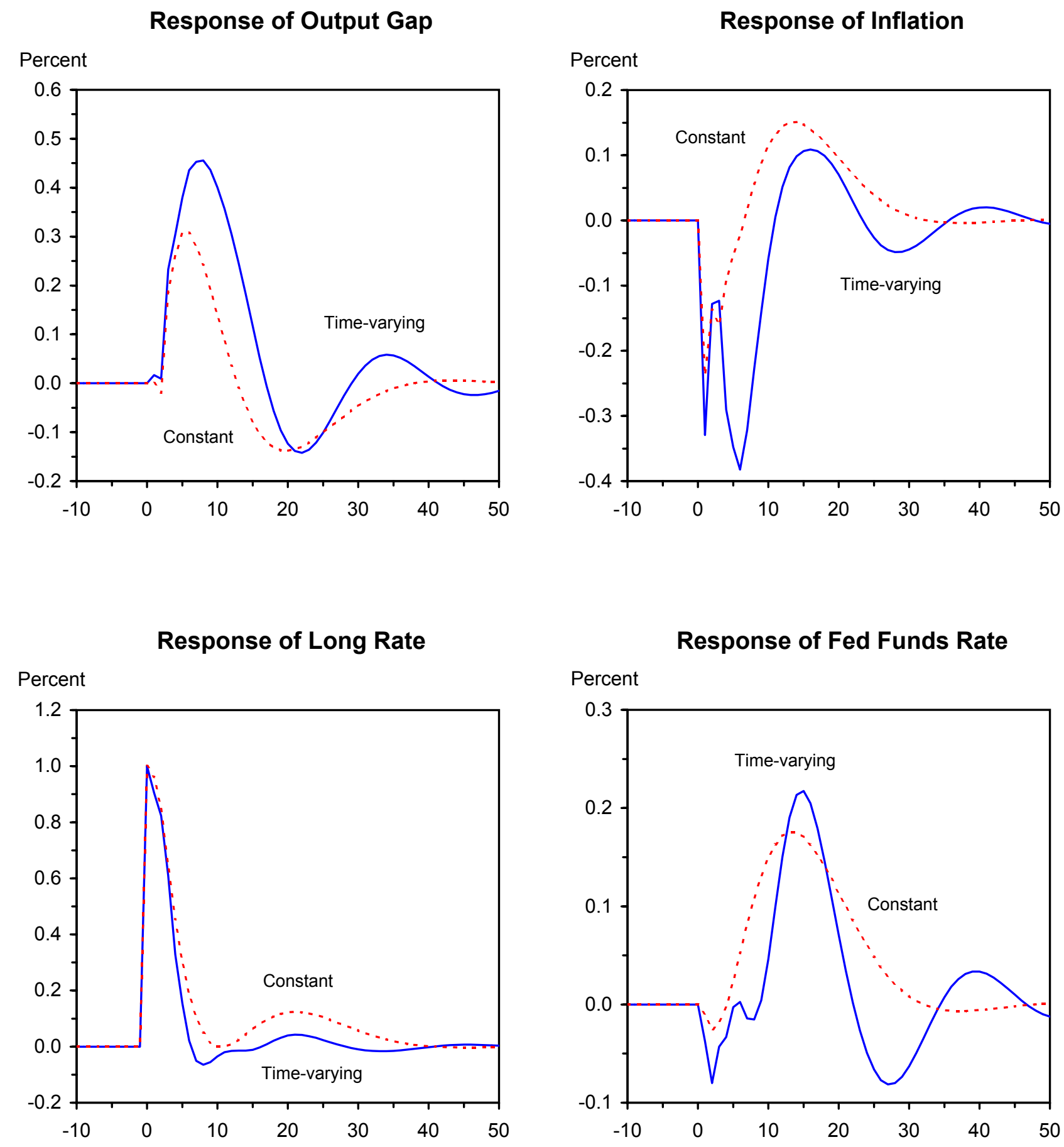
Figure 8: Impulse Responses to a Transitory Policy Shock
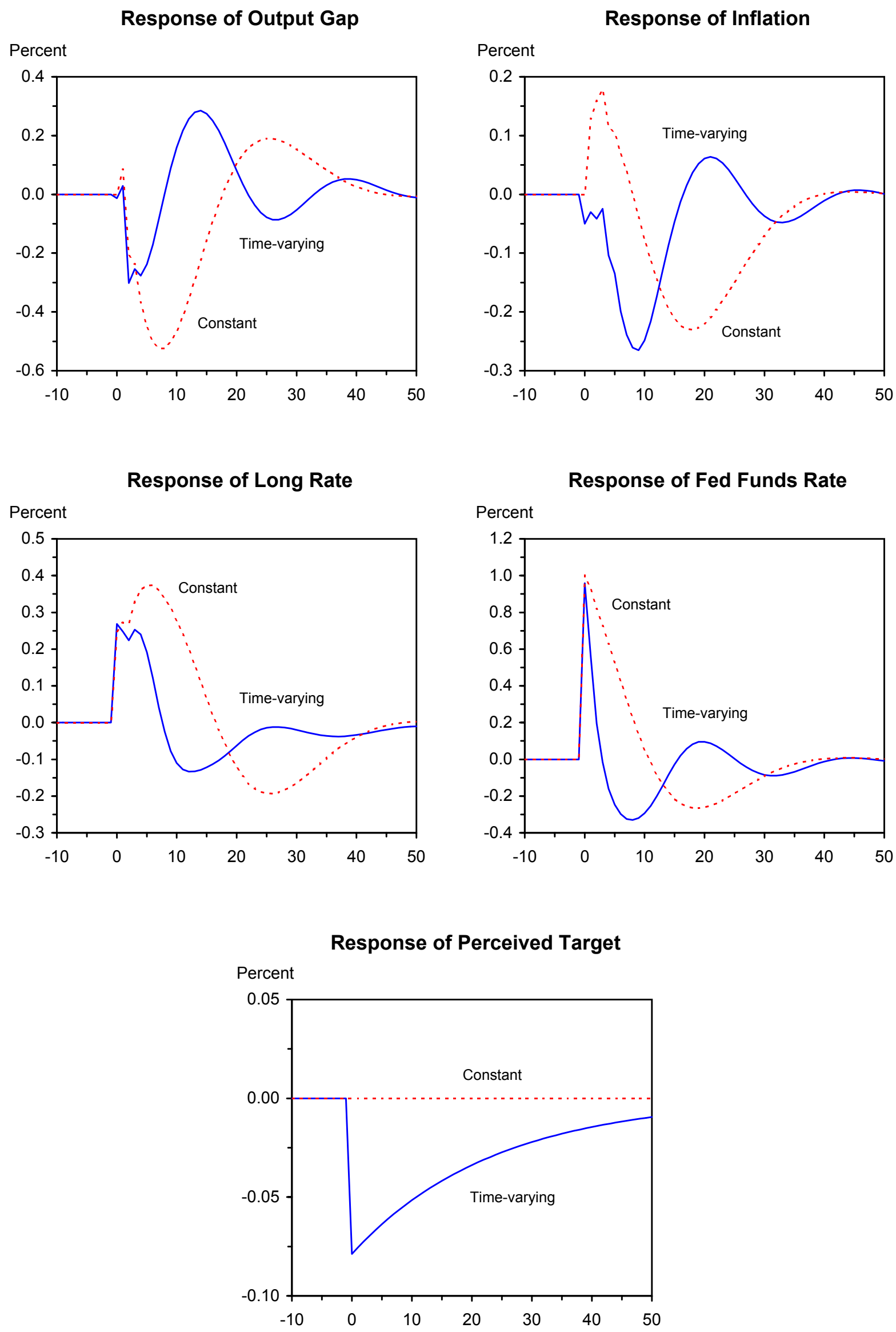
Figure 9: Impulse Responses to a Permanent Target Shock

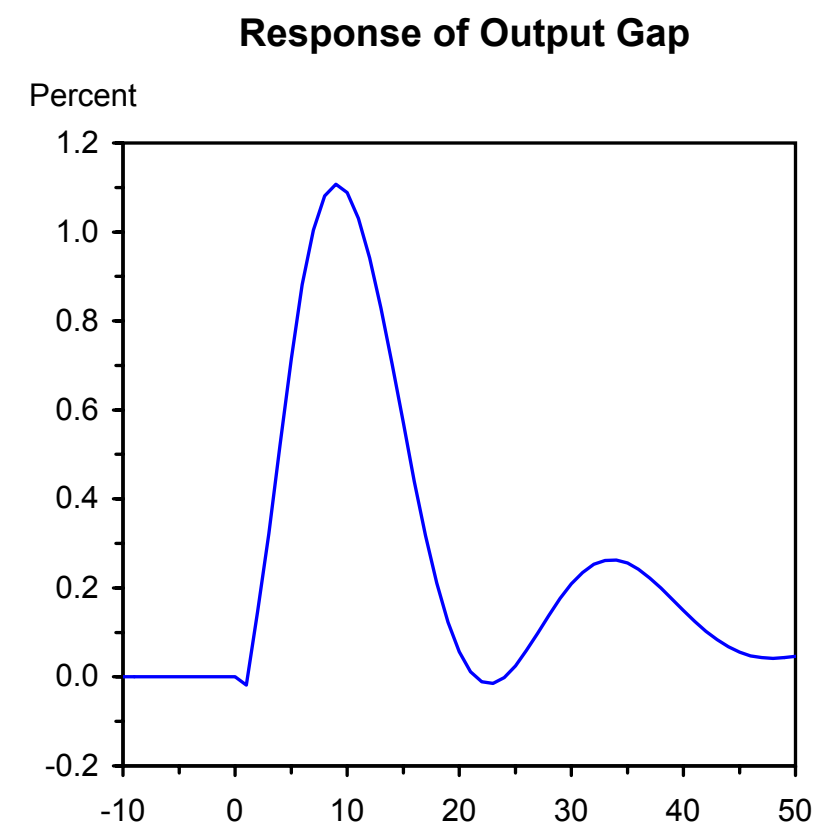

\section{Response of Inflation, Target, and Perceived Target}

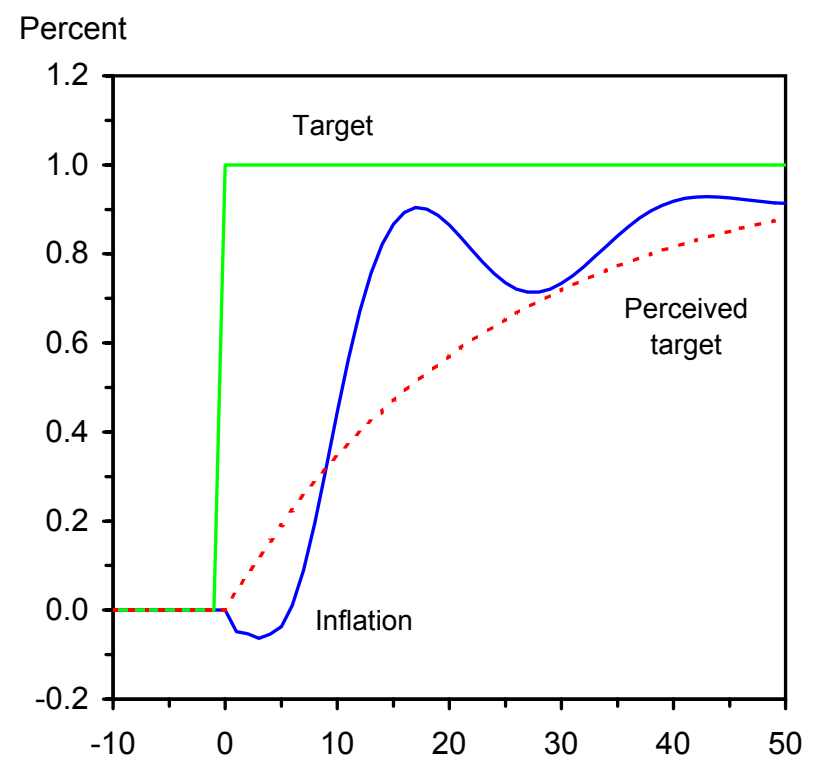

Response of Long Rate and Perceived Target

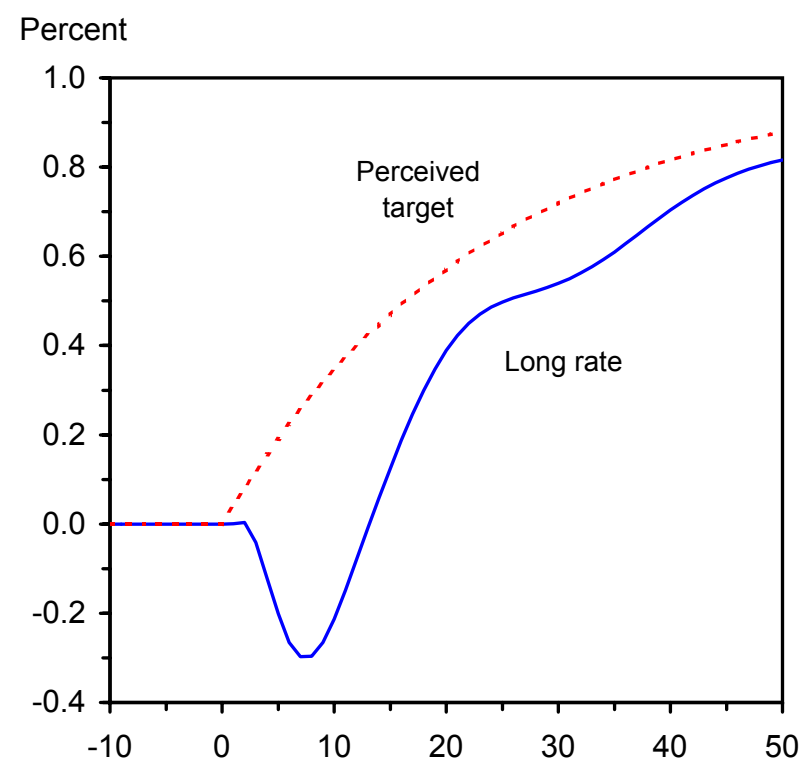

\section{Response of Fed Funds Rate}

Percent

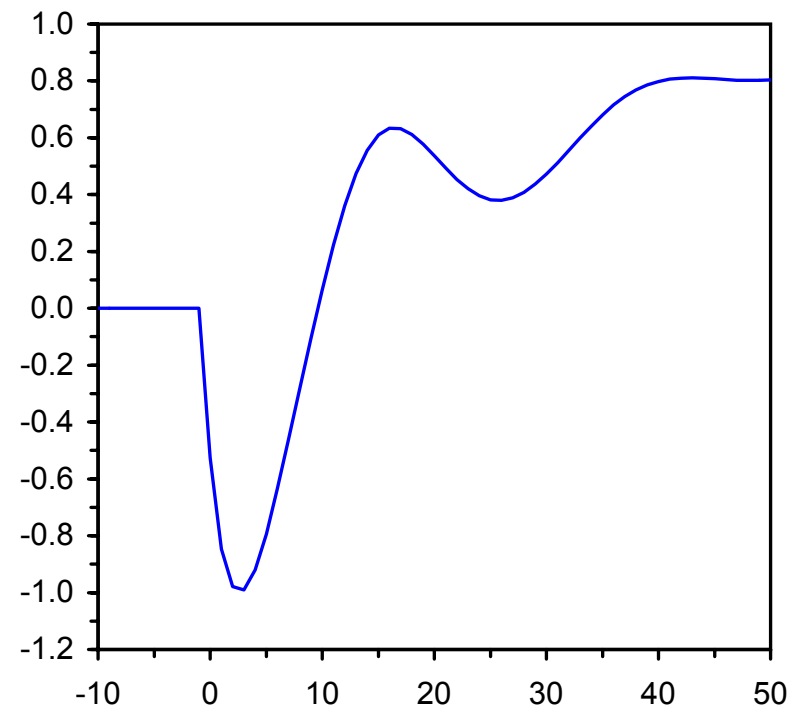


Figure 10: Impulse Responses to an Expectations Shock

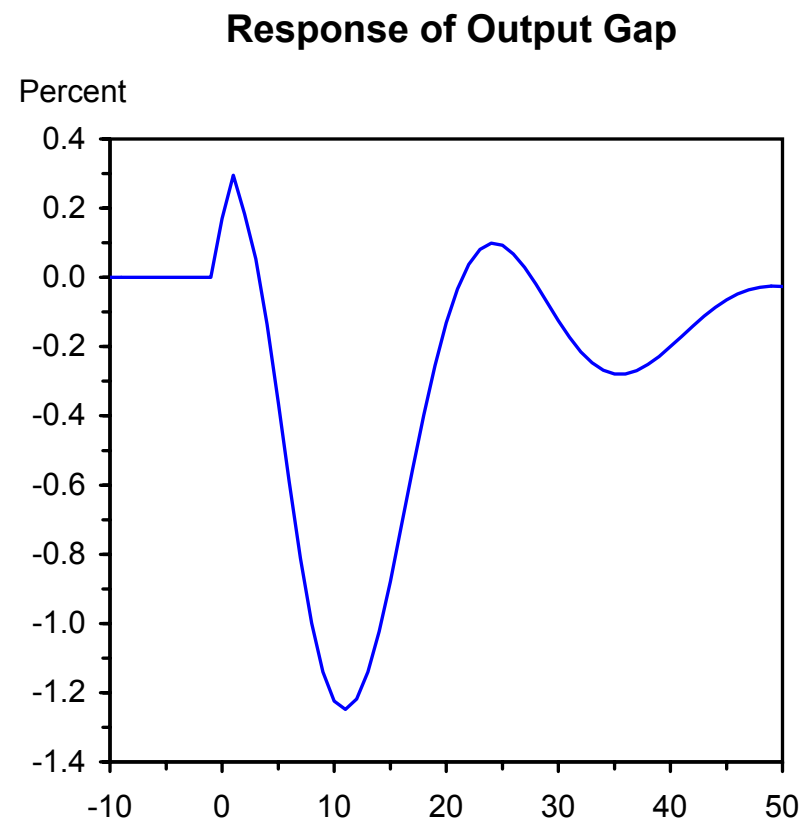
Response of Inflation, Target, and Perceived Target
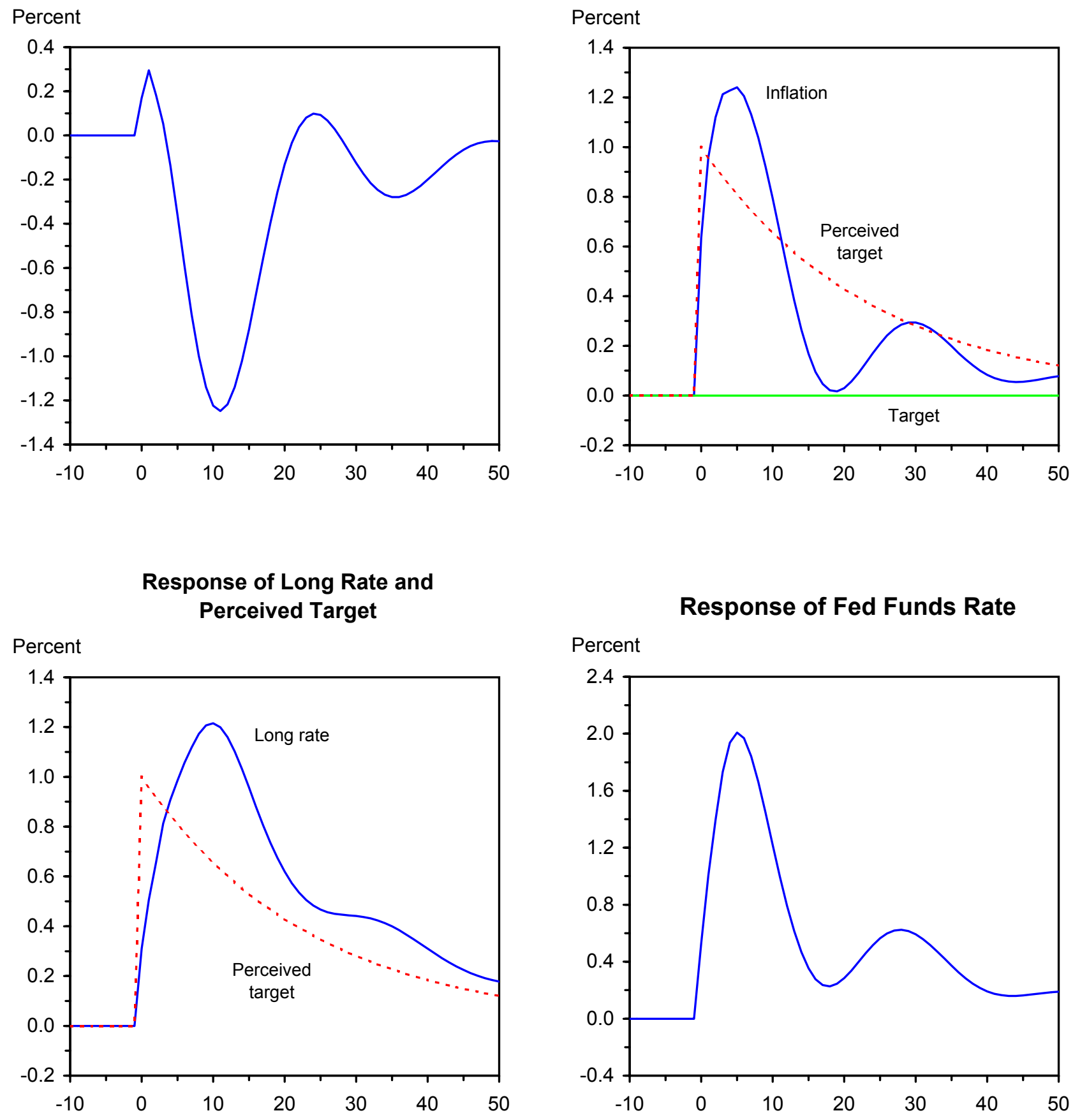
Figure 11: Implications of Faster Learning for Impulse Responses to a Transitory Policy Shock
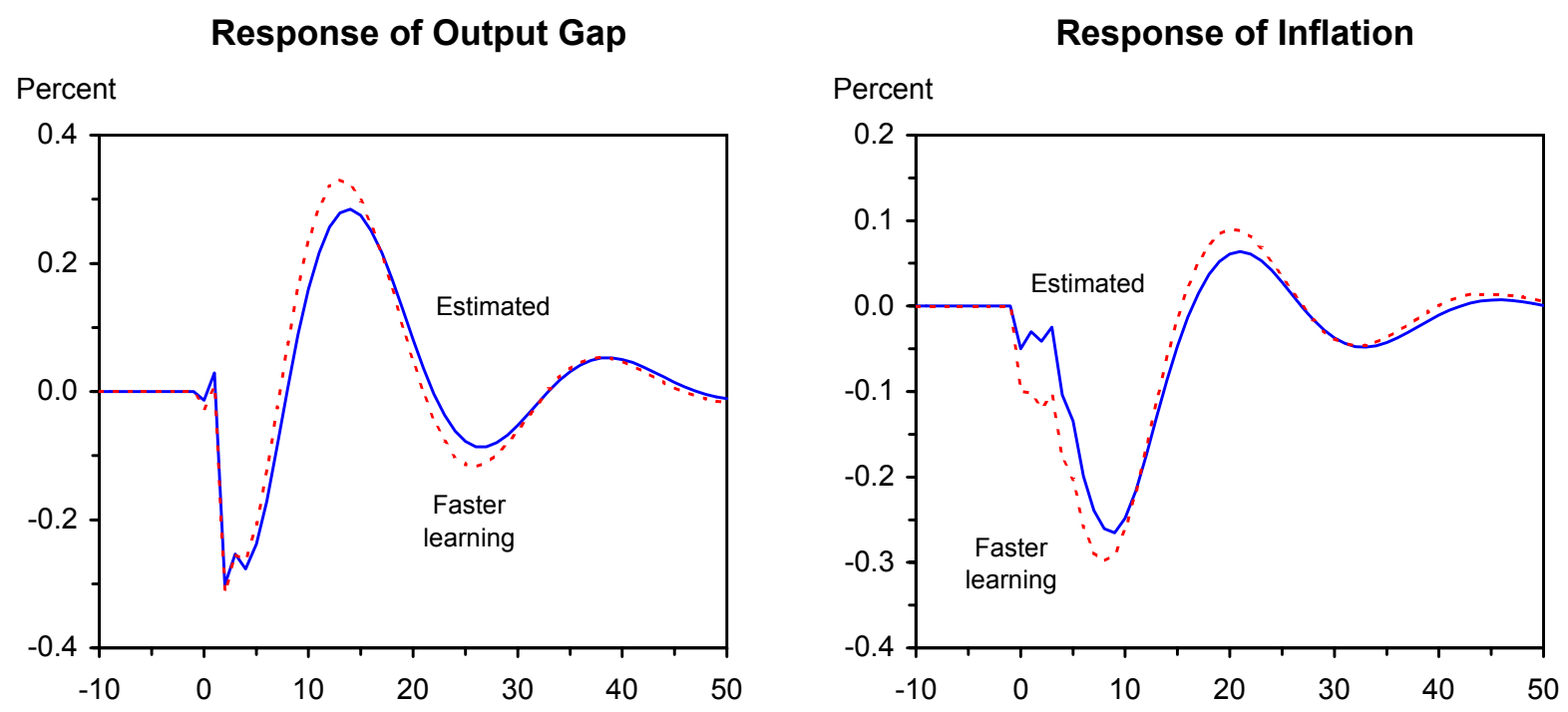

\section{Response of Long Rate}
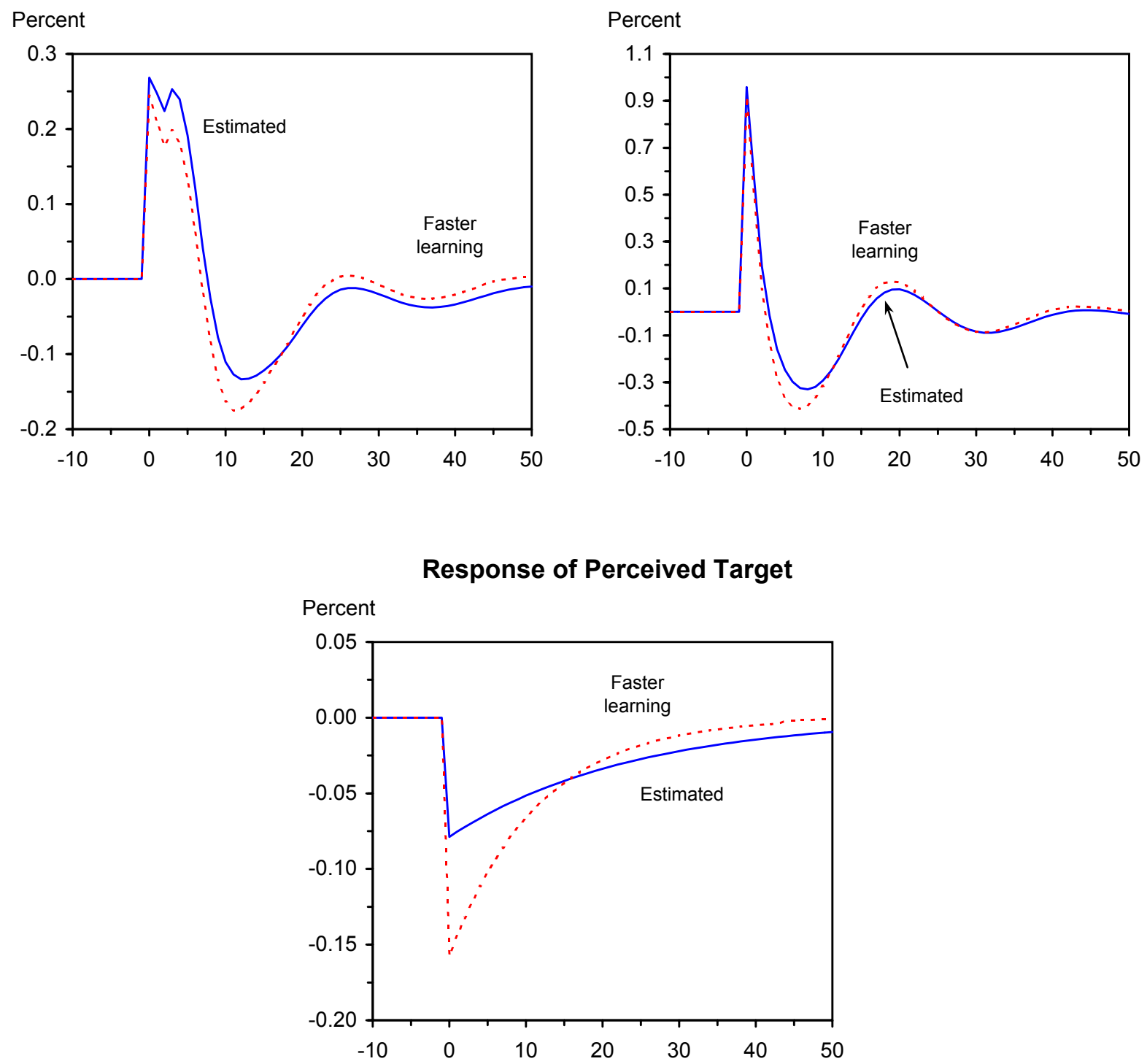
Figure 12: Implications of Faster Learning for Impulse Responses to a Permanent Target Shock
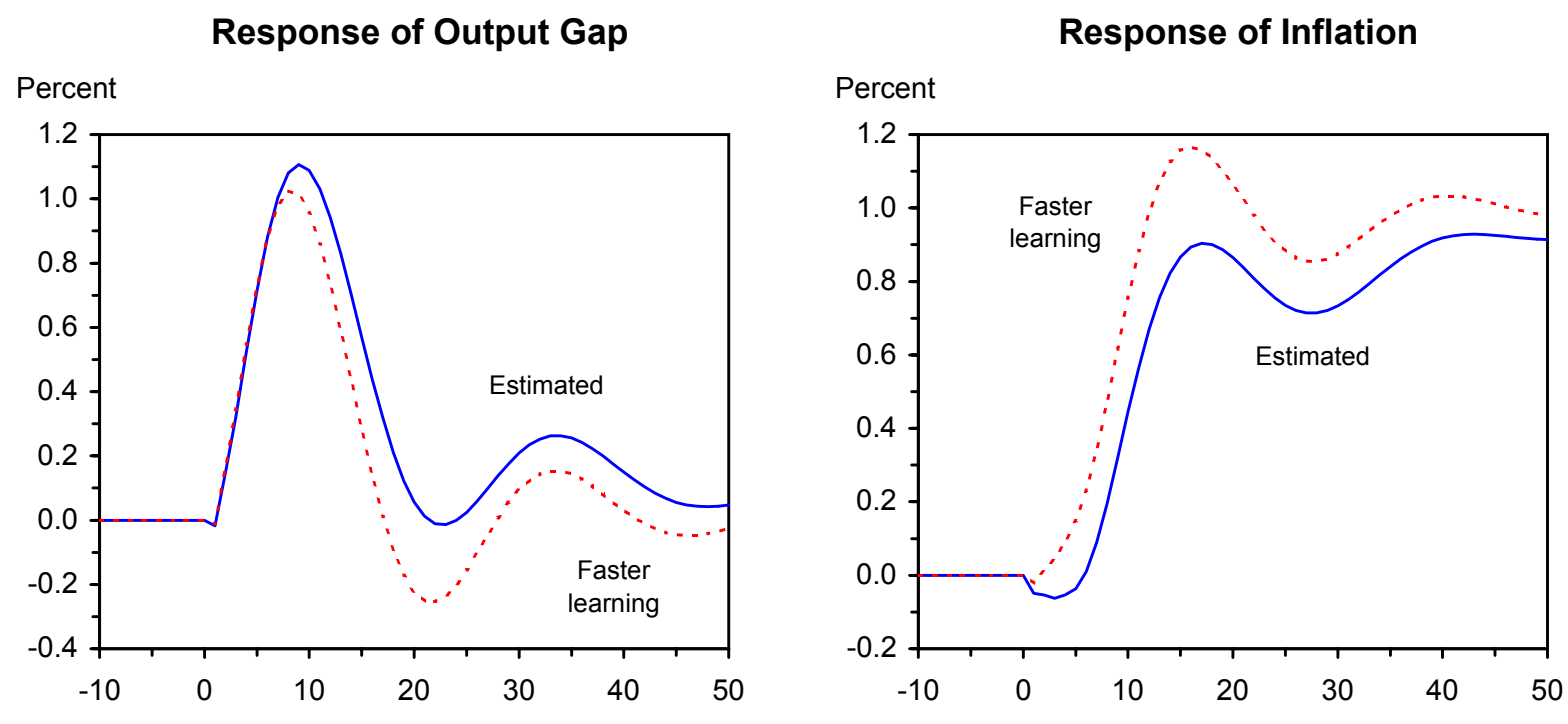

Response of Long Rate

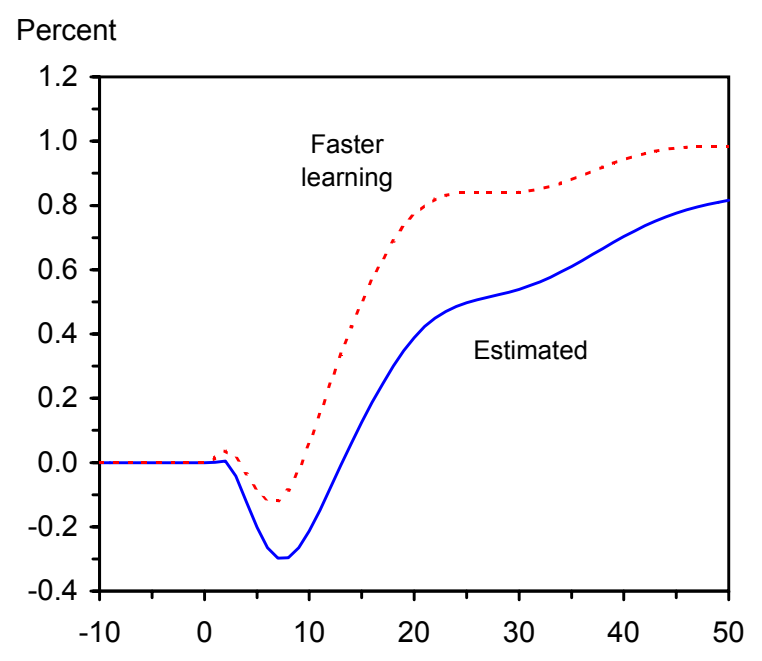

\section{Response of Fed Funds Rate}

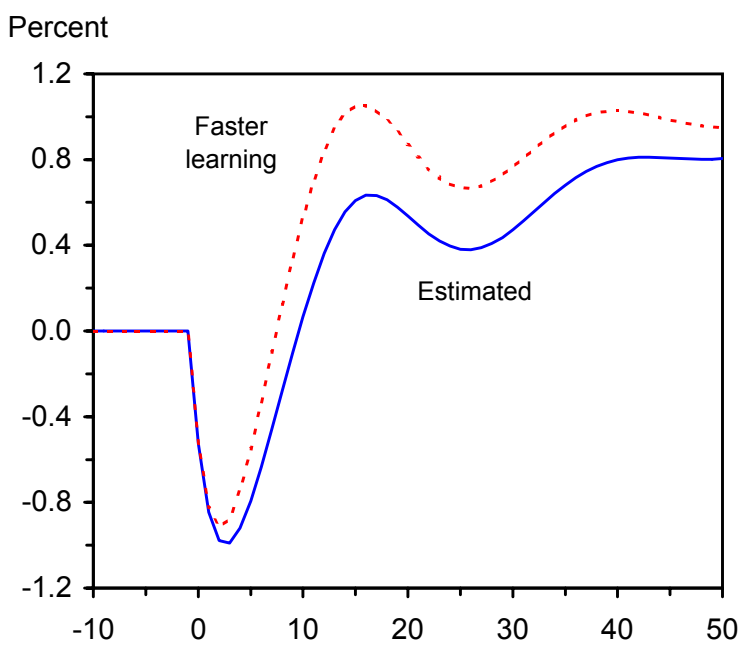

Response of Perceived Target and Target

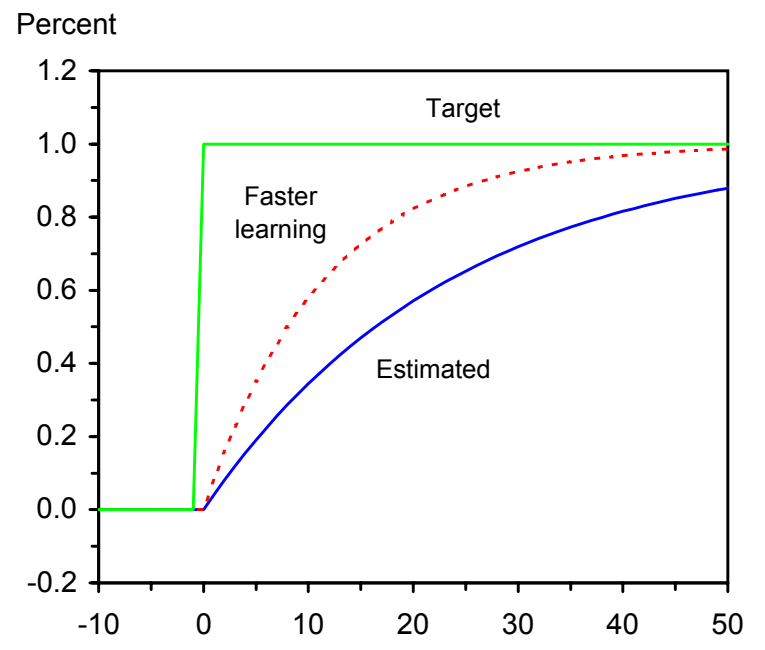




\section{CFS Working Paper Series:}

\begin{tabular}{|c|c|c|}
\hline No. & Author(s) & Title \\
\hline $2003 / 34$ & Issam Hallak & $\begin{array}{l}\text { Courts and Sovereign Eurobonds: Credibility of } \\
\text { the Judicial Enforcement of Repayment }\end{array}$ \\
\hline $2003 / 35$ & $\begin{array}{l}\text { Torben G. Andersen } \\
\text { Tim Bollerslev } \\
\text { Francis X. Diebold }\end{array}$ & $\begin{array}{l}\text { Some Like it Smooth, and Some Like it Rough: } \\
\text { Untangling Continuous and Jump Components in } \\
\text { Measuring, Modeling, and Forecasting Asset } \\
\text { Return Volatility }\end{array}$ \\
\hline $2003 / 36$ & Reinhard H. Schmidt & $\begin{array}{l}\text { Corporate Governance in Germany: } \\
\text { An Economic Perspective }\end{array}$ \\
\hline $2003 / 37$ & $\begin{array}{l}\text { George W. Evans } \\
\text { Bruce McGough }\end{array}$ & $\begin{array}{l}\text { Monetary Policy, Indeterminacy } \\
\text { and Learning }\end{array}$ \\
\hline $2003 / 38$ & $\begin{array}{l}\text { James Bullard } \\
\text { In-Koo Cho }\end{array}$ & Escapist Policy Rules \\
\hline $2003 / 39$ & $\begin{array}{l}\text { Seppo Honkapohja } \\
\text { Kaushik Mitra }\end{array}$ & $\begin{array}{l}\text { Performance of Inflation Targeting Based On } \\
\text { Constant Interest Rate Projections }\end{array}$ \\
\hline $2003 / 40$ & $\begin{array}{l}\text { Athanasios Orphanides } \\
\text { John C. Williams }\end{array}$ & $\begin{array}{l}\text { Imperfect Knowledge, Inflation Expectations, } \\
\text { and Monetary Policy }\end{array}$ \\
\hline $2003 / 41$ & $\begin{array}{l}\text { Sharon Kozicki } \\
\text { P.A. Tinsley }\end{array}$ & $\begin{array}{l}\text { Permanent and Transitory Policy Shocks in an } \\
\text { Empirical Macro Model with Asymmetric } \\
\text { Information }\end{array}$ \\
\hline $2003 / 42$ & $\begin{array}{l}\text { Mordecai Kurz } \\
\text { Hehui Jin } \\
\text { Maurizio Motolese }\end{array}$ & $\begin{array}{l}\text { The Role of Expectations in Economic } \\
\text { Fluctuations and the Efficacy of Monetary Policy }\end{array}$ \\
\hline $2003 / 43$ & $\begin{array}{l}\text { William A. Brock } \\
\text { Steven N. Durlauf } \\
\text { Kenneth D. West }\end{array}$ & $\begin{array}{l}\text { Policy Evaluation in Uncertain Economic } \\
\text { Environments }\end{array}$ \\
\hline $2003 / 44$ & $\begin{array}{l}\text { Timothy Cogley } \\
\text { Sergei Morozov } \\
\text { Tomas J. Sargent }\end{array}$ & $\begin{array}{l}\text { Bayesian Fan Charts for U.K. Inflation: } \\
\text { Forecasting and Sources of Uncertainty in an } \\
\text { Evolving Monetary System }\end{array}$ \\
\hline
\end{tabular}

Copies of working papers can be downloaded at http://www.ifk-cfs.de/ 